\title{
Influence of Advanced Structural Modeling Technique, Mainshock-Aftershock Sequences, and Ground-Motion Types on Seismic Fragility of Low-Rise RC Structures
}

\author{
Mohammad R Salami ${ }^{1}$, Mohammad M Kashani ${ }^{2}$ and Katsuichiro Goda ${ }^{3}$ \\ ${ }^{1}$ School of Engineering and the Built Environment, Birmingham City University, B5 5JU, United Kingdom \\ ${ }^{2}$ Faculty of Engineering and the Environment, University of Southampton, SO17 1BJ, United Kingdom \\ ${ }^{3}$ Department of Civil Engineering, University of Bristol, BS8 1TR, United Kingdom
}

\begin{abstract}
Large earthquakes are rare natural hazards, having catastrophic impact on society due to loss of lives, damage to constructed facilities, and business interruption. Because of damage accumulation due to the main strong shaking, aftershocks potentially endanger the safety of residents and subsequently increase financial loss due to downtime and repair costs. Therefore, accurate prediction of the seismic performance of structures in the post-earthquake stage is critical for disaster risk mitigation. This paper employs an advanced structural modeling technique, which can simulate various features of cyclic degradation in material and structural components using nonlinear fiber beamcolumn elements. The model accounts for inelastic buckling and low-cycle fatigue degradation of longitudinal reinforcement and can simulate multiple failure modes of reinforced concrete structures under dynamic loading. Furthermore, a comprehensive ground motion selection accounting for multiple types of ground motions, such as shallow crustal, deep inslab, and subduction earthquakes, is implemented. Finally, a new set of fragility curves has been developed for each ground motion type, which accounts for the aftershock effects and influence of ground motion types on cyclic degradation and failure modes of low-rise reinforced concrete structures. It was found that slight and moderate damage is not significantly affected by major aftershocks for different ground motions types. However, considering aftershocks increases the probability of exceedance of damage for extensive and complete damage up to $5 \%$ and $10 \%$ for inslab and crustal event, respectively. The proposed methodology significantly improves the accuracy of seismic risk and vulnerability assessment by reducing the uncertainties associated with structural modeling and variability of earthquake ground motions.
\end{abstract}

Keywords: RC structures, Inelastic buckling, Low-cycle fatigue, Real mainshock-aftershock sequence, Ground motion type.

\section{Introduction}

Over the past decades, several earthquakes occurred with damaging aftershocks and imposed enormous hazard and risk to several urban cities around the world. An example of major mainshock-aftershock (MSAS) events is the $19^{\text {th }}$ September 1985 , Michoacan earthquake in Mexico City with a moment magnitude (M) of 8.0 and an M 7.6 aftershock that occurred a day after the main earthquake. Many medium-rise reinforced concrete (RC) buildings in Mexico City suffered moderate to extensive structural damage because of the mainshock [1]. The strong aftershock magnified the structural damage causing the collapse of many buildings that were already damaged during the mainshock [2]. More recent damaging MSAS events are the $4^{\text {th }}$ September 2010, M 7.0 Darfield event in New Zealand, followed by the $22^{\text {nd }}$ February 2011, M 6.2 Christchurch event, causing extensive damage to unrepaired structures [3], and the $11^{\text {th }}$ March 2011, M 9.0 Tohoku earthquake in Japan, with numerous major aftershocks as large as M 7.9 [4]. These historical events indicate that neglecting 
aftershock hazard and risk may lead to a biased assessment of the seismic performance of structures, which jeopardizes the integrity of designed and constructed structures. Reliable seismic performance evaluation and quantifying the potential failure risk of existing $\mathrm{RC}$ structures require accurate modeling of nonlinear behavior of these structures under cyclic dynamic loading.

Numerous studies have been carried out to investigate the performance of structures by considering aftershock sequences [5-11]. In particular, Hatzigeorgiou and Beskos [8] conducted an extensive parametric study to estimate the inelastic displacement ratio (i.e. the ratio of the maximum inelastic displacement to the maximum elastic displacement) of inelastic single-degree-of-freedom (SDOF) systems. They found that the repeated earthquake phenomenon has a significant effect on the maximum inelastic displacement of SDOF systems. Additionally, it was shown that SDOF systems with negative post-yield stiffness (i.e. systems with softening behavior, such as RC buildings) have higher displacement demands compared to hardening systems.

Owing to improvements in computational modeling and advanced computers over the last decades, multidegree-of-freedom (MDOF) systems have been used to consider more realistic structural modeling, by accounting for higher mode interaction and force distribution among structural components [12-15]. Knowing that structures with softening behavior are more susceptible to additional damage due to aftershocks, the response of RC structures under multiple earthquakes has gained much attention among researchers in earthquake engineering community. Faisal et al. [16], Di Sarno [17], Ebrahimian et al. [18], Goda and Tesfamariam [19], Abdelnaby and Elnashai [20], and Hosseinpour and Abdelnaby [21] studied the performance of RC buildings under MSAS sequences. Their studies confirmed that there is a lack of conservatism in the safety of conventionally designed structures subjected to multiple earthquakes. Recently, Raghunandan et al. [22] conducted an extensive study on aftershock collapse vulnerability assessment of modern ductile RC frame structures located in California. They concluded that the collapse capacity of structure is unaffected by the aftershock when the structure is not severely damaged during the mainshock. However, if the structure is extensively damaged during the mainshock, the probability of collapse of the structure will be significantly increased during the aftershock. Finally, Jeon et al. [23] proposed a framework of aftershock fragility assessment for RC buildings. In their study, two-dimensional non-ductile RC frames with 4, 8, and 12 stories (low-rise, mid-rise, and high-rise) located in California were considered. Their results showed that the increase in vulnerability associated with aftershock damage is significant for frames exhibiting remarkable damage due to the mainshock. Conversely, if the damage state due to the mainshock is slight or moderate, the increased damage potential associated with the aftershocks is minimal (less than $4 \%$ ).

A review of the literature has shown the improvements in structural modeling and ground motion record generation/selection. Using finite element (FE) models subjected to an extensive set of real MSAS sequences, instead of SDOF systems and/or artificial records (e.g. randomized/back-to-back methods), increases the accuracy of structural performance assessments. However, influences of advanced structural modeling, damage quantification, and ground motion characteristics on seismic performance assessments of structures considering MSAS have not been investigated, and thus further research is warranted. In particular, considerations of axialflexural force interaction between elements, cracking/crushing of cover and core concrete, longitudinal bar buckling and fracture due to fatigue are the most critical aspects of an advanced structural modeling to simulate damage accumulation in the structure realistically. A fiber beam-column model proposed in this study integrates all above-mentioned sources of damage in simulation and provides significant improvements over conventional 
lumped plasticity models.

This paper quantifies the impact of real MSAS sequences for a 2-story RC structure located in Seattle, US. An advanced ground motion selection procedure has been used to consider complex hazard and seismicity of the specific site. Considerations of shallow crustal, deep inslab, and subduction (interface) earthquakes and advanced FE model that accounts for structural deterioration and degradation, such as longitudinal bar buckling and fatigue, distinguish this study from previous studies. The impact of ground motion characteristics, such as significant duration, peak ground acceleration (PGA), and energy density, have been investigated in detail. Capturing different mechanisms of damage and failure modes due to different ground motion types requires an advanced structural modeling which is one of the main motivations and novelties of this study. The following section is devoted to a description of the RC frame building. The MSAS ground motion selection is explained subsequently and followed by results and discussion at the end of this paper.

\section{RC frame building model development}

\subsection{Proposed RC building}

The $\mathrm{RC}$ building considered in this paper is a 2-story moment-resisting frame taken from the prototype buildings developed by Haselton [24]. The proposed frame represents a class of ductile RC frames designed according to the seismic code provisions of the 2003 IBC [25], ASCE 7-02 [26], and ACI 318-02 [27] to ensure the ductile behavior, which prevents or delays sudden collapse under seismic loading. The ductile frame was designed for a high seismic hazard site, corresponding to the NEHRP soil category D (soil class $S d, S_{m s}=1.5 \mathrm{~g}$ and $S_{m l}=0.9 \mathrm{~g}$, where $S_{m s}$ is the maximum considered earthquake (MCE) spectral acceleration at short period and $S_{m l}$ is the MCE spectral acceleration at $1.0 \mathrm{~s}$ period). The geometry and elements details are presented in Fig.1a.

\subsection{Finite element model development}

To evaluate the seismic performance of RC structures realistically, the structural model should be capable of simulating the nonlinear dynamic structural response from small deformation (crack initiation and tension stiffening) up to large deformation (collapse). This is especially important for assessing monetary loss due to frequent low-intensity ground motions over time [24]. On the other hand, fatality risks are directly related to collapse prediction of the structure. It is more common to use lumped plasticity models in which plastic hinges at two ends of the column/beam are represented by the nonlinear backbone curve of the structural element. Despite the efficiency of lumped plasticity models (i.e. runtime and convergence), distributed plasticity nonlinear fiber beam-column models have significant advantages over the lumped plasticity approach in: i) capturing the axial-flexural interaction for both strength and stiffness; ii) incorporating the effects of concrete tensile strength and tension stiffening; and iii) providing a generic modeling platform to capture inelastic behavior of RC components with any geometry and reinforcement detail (lumped plasticity models only work for specific cases fitted to experimental data). The main limitation of the conventional fiber models available in the literature is their inability to simulate collapse behavior [24]. The improved fiber beam-column model employed in this study significantly increases the capabilities of RC structural modeling by capturing the inelastic buckling and low-cycle fatigue degradation of longitudinal reinforcing bars. Previously, Kashani et al. [28-31] developed a modeling technique for RC columns. In this paper, the same modeling technique is 
employed for RC building frames.



(a)
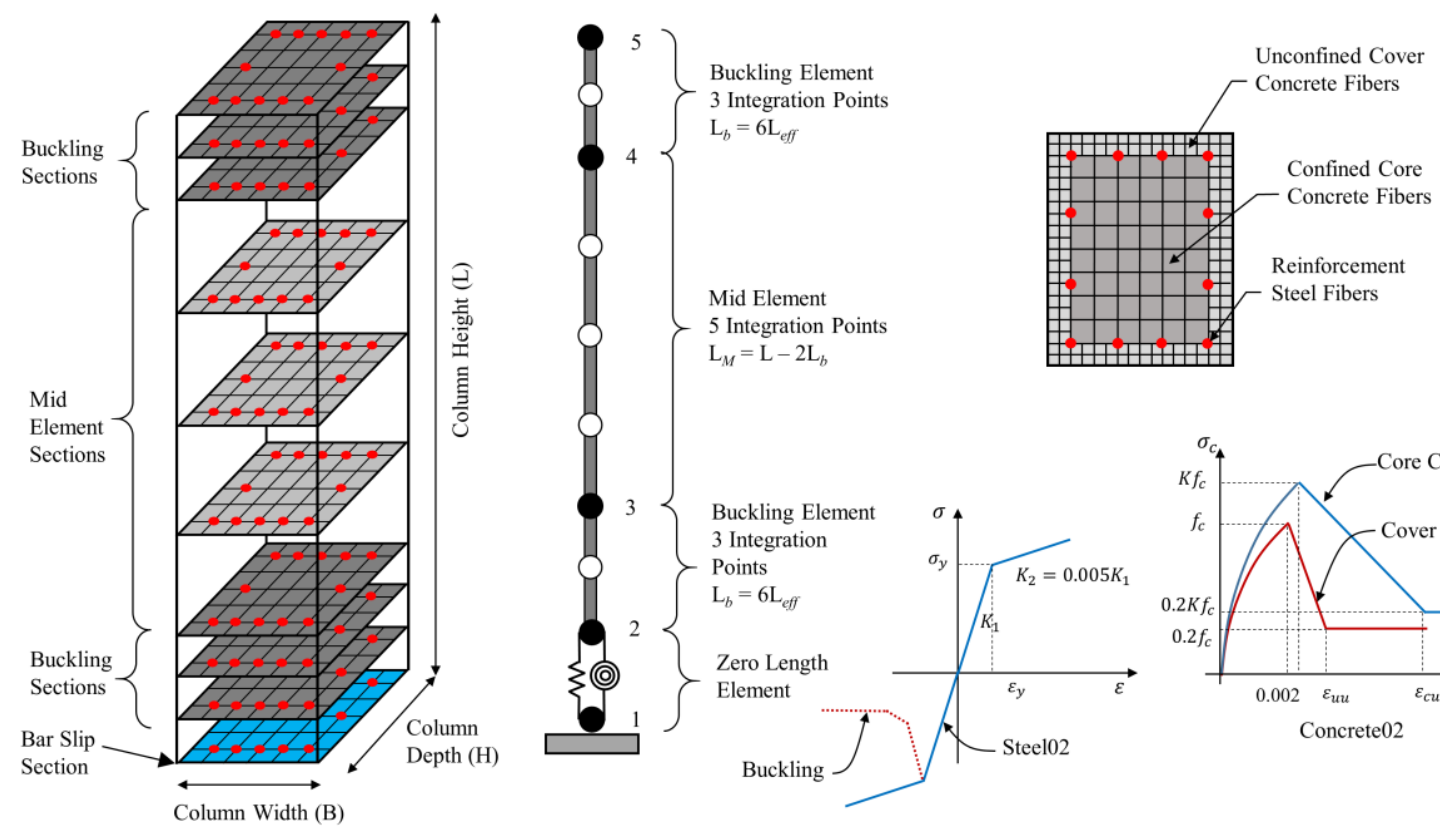

(b)

Fig. 1. Structural details and idealized FE model of the 2-story RC building: (a) geometrical and RC details and (b) FE model description using nonlinear fiber beam-column elements and steel/concrete uniaxial material

The structural model in this study employs force-based nonlinear fiber beam-column elements available in OpenSees [32]. In this method, the whole column is modeled using three elements (Fig.1b) with a total length of the end elements equal to $6 \mathrm{~L}_{\text {eff }}$ where $\mathrm{L}_{\text {eff }}$ is the buckling length. The calculation of $\mathrm{L}_{\text {eff }}$ is based on the method suggested by Dhakal and Maekawa [33]. They proposed an iterative procedure, shown in Fig.2, to calculate the required stiffness to sustain buckling mode and buckling length of reinforcing bars. Solving the following equations that involve the stiffness of horizontal ties and axial loads acting of longitudinal refinements leads to finding $L_{\text {eff. }}$ 


$$
\begin{gathered}
E I=\frac{E_{s} I}{2} \sqrt{\frac{\sigma_{y}}{400}} \\
\frac{2 \pi^{4} E I}{n^{2} s^{2}}+\sum_{i=1}^{n} \frac{c_{i} K_{n}}{4}\left(1-\cos \frac{2 i \pi}{n}\right)^{2}-\frac{P_{n} \pi^{2}}{2 n s}=0 \\
\frac{2 \pi^{4} E I}{(n+1)^{2} s^{2}}+\sum_{i=1}^{n+1} \frac{c_{i} K_{n}}{4}\left(1-\cos \frac{2 i \pi}{n+1}\right)^{2}-\frac{P_{n} \pi^{2}}{2(n+1) s}=0 \\
K_{t}=\frac{E_{t} A_{t}}{l_{e}} \times \frac{n_{l}}{n_{b}}
\end{gathered}
$$

where $E_{s}$ is the elastic modulus, and $\sigma_{y}$ is the yield stress of the longitudinal reinforcement in MPa. EI is the average inelastic flexural rigidity of longitudinal reinforcement (calibrated empirically using experimental data). $s$ is the horizontal tie spacing, $n$ in the buckling mode, $K_{n}$ and $P_{n}$ are the critical spring stiffness and axial loads corresponding the $n$th mode, respectively. $K_{t}$ is the stiffness of lateral ties, $E_{t}, A_{t}$, and $l_{e}$ are elastic modulus, cross-sectional area and the leg-length of ties, respectively. The values of $n_{l}$ and $n_{b}$ represent the common arrangements of longitudinal and lateral reinforcement which are available in [33]. For forced-based elements at top/bottom, three integration points are used, and for the middle part of the column elements with five integration points are considered. The numbers of fibers and the section discretization method are based on the recommendations provided by Berry and Eberhard [34]. The same strategy was also used for beams, considering that there is a possibility of rebar buckling due to high bending moment at each end of the beams. The zerolength bond-slip elements are used at the level of the foundation to simulate the reinforcement slippage at column-foundation interface. Further details of the modeling technique and experimental validation are available in Kashani et al. [28, 31].

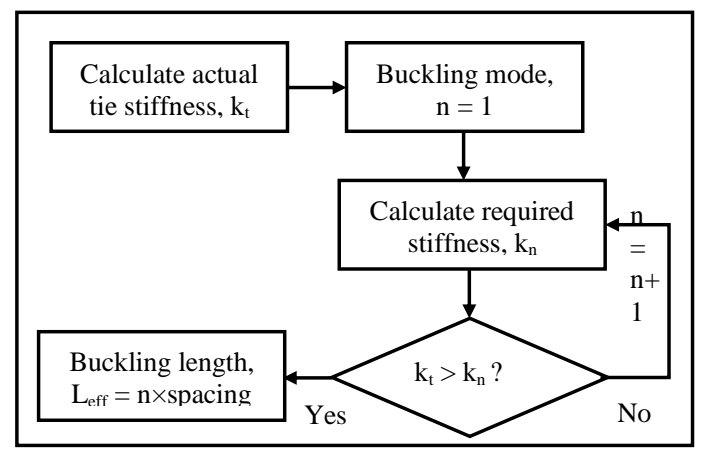

Fig. 2. Flow-chart of buckling length determination [33]

\subsection{Uniaxial material models}

To simulate a cyclic response of the reinforcing bars, a uniaxial material model is defined by the GiuffreMenegotto-Pinto (GMP) [35] equations which have been modified by Filippou et al. [36]. This model is available in OpenSees and is known as Steel02 uniaxial material model (Fig.1b). The Steel02 material model accounts for the Bauschinger effect [37]. However, it does not account for cyclic strength and stiffness degradation due to bar buckling and fatigue. In this study, a phenomenological material model of reinforcing bars developed by Kashani et al. [29] is employed and implemented in OpenSees using a uniaxial Hysteretic material model. This model simulates the inelastic buckling of reinforcing bars. The generic Fatigue material model available in OpenSees is used to simulate low-cycle fatigue degradation of reinforcing bars. The Fatigue 
material uses a modified rainflow cycle counting algorithm to accumulate damage in a material using Miner's rule [38]. The material model can be wrapped to any steel model (or any other uniaxial materials) without changing the stress-strain state of the parent material. Once the Fatigue material reaches a damage index of 1.0, the stress of the parent steel material becomes zero. The calibrated parameters for Fatigue material constants, which account for the influence of inelastic buckling of low-cycle fatigue behavior of reinforcing bars, are taken from an experimental study conducted by Kashani et al. [29]. An illustration of the cyclic response of the conventional Steel02 model in OpenSees and the Fatigue material model wrapped to Hysteretic model is shown in Fig.3.

In this paper, the material model developed by Park et al. [39] is used for concrete. This model is known as Concrete02 in OpenSees shown in Fig. 1b. It has a parabolic curve up to the maximum concrete stress and a linear post-peak softening branch afterward. In another study [31] by the authors of this paper, it was found that the Park et al. model can simulate the nonlinear flexural behavior of rectangular RC components more accurately compared to Mander's model [40] (known as Concrete04 in OpenSees), which is more suitable for circular RC components.



Fig. 3. Cyclic response of the uniaxial material model used for fibers in column and beam, conventional reinforcing material model (Steel02) and Hysteretic material model combined with Fatigue material model

(Normalized by yield stress/strain)

After generating the FE model for the 2-story RC building, an eigenvalue analysis is performed after the gravity load analysis to compute the natural period of vibration of the structure, $T 1(T 1=0.5 s)$. The computed $T 1$ of the proposed model in this paper is slightly less than $T l=0.6 s$ reported by Haselton [24] using the lumped plasticity model. Monotonic nonlinear pushover analysis was performed, and the lateral force-deformation for the first story and the corresponding damage level at each inter-story drift ratio are shown in Fig.4. The fiber model predicts the maximum story shear slightly more than the value calculated using the lumped plasticity model [24]. 


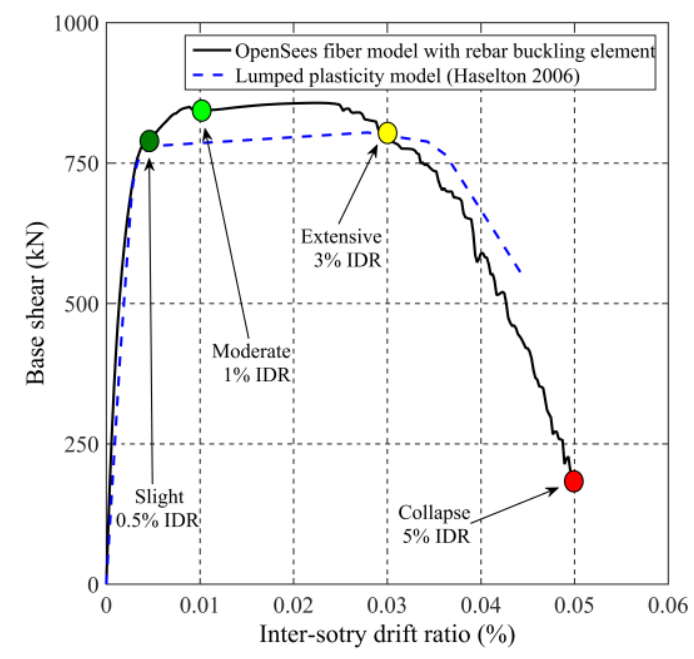

Fig. 4. Static nonlinear pushover curves for the fiber model (this study) and lumped plasticity model by Haselton

\section{Ground motion selection methodology}

\subsection{Site location and seismicity}

The proposed building is located at a typical urban site condition in Seattle, Washington State, US (latitude/longitude $=47.609^{\circ} \mathrm{N} / 122.333^{\circ} \mathrm{W}$ ). Based on geological surveys and historical events, Washington has complex seismogenic faults. Western Washington lies in the Cascadia subduction zone [41]. An M 9 megathrust earthquake in the Cascadia subduction zone has the potential of extensive destruction and economic loss from Vancouver in Canada to Northern California in the US. In addition to the offshore megathrust subduction zone, there are several faults in the upper crust that could cause significant earthquake damage due to proximity to the urban areas and shallow depth (5 to $20 \mathrm{~km}$ ). Fig. 5 presents the crustal faults in the Seattle basin. The Seattle fault has been discovered to have the potential of a shallow strong earthquake of M 7 [42]. Moreover, buildings in Seattle are subjected to deep inslab earthquakes, which occur at the depth of 40 to $60 \mathrm{~km}$ under the Puget Sound zone. Inslab earthquakes as large as M 7.5 are expected. Two damaging historical events were the 1949 event near Olympia (southwest of Tacoma) and the 1965 event near the Seattle-Tacoma International Airport [42]. Since the selected site is affected by a complex seismicity from various seismic sources (crustal, inslab, and interface), a comprehensive ground motion selection is essential for seismic performance assessment of buildings located in Seattle. In the following, a rigorous ground motion selection is conducted by including different ground motion sources for the target building site. 


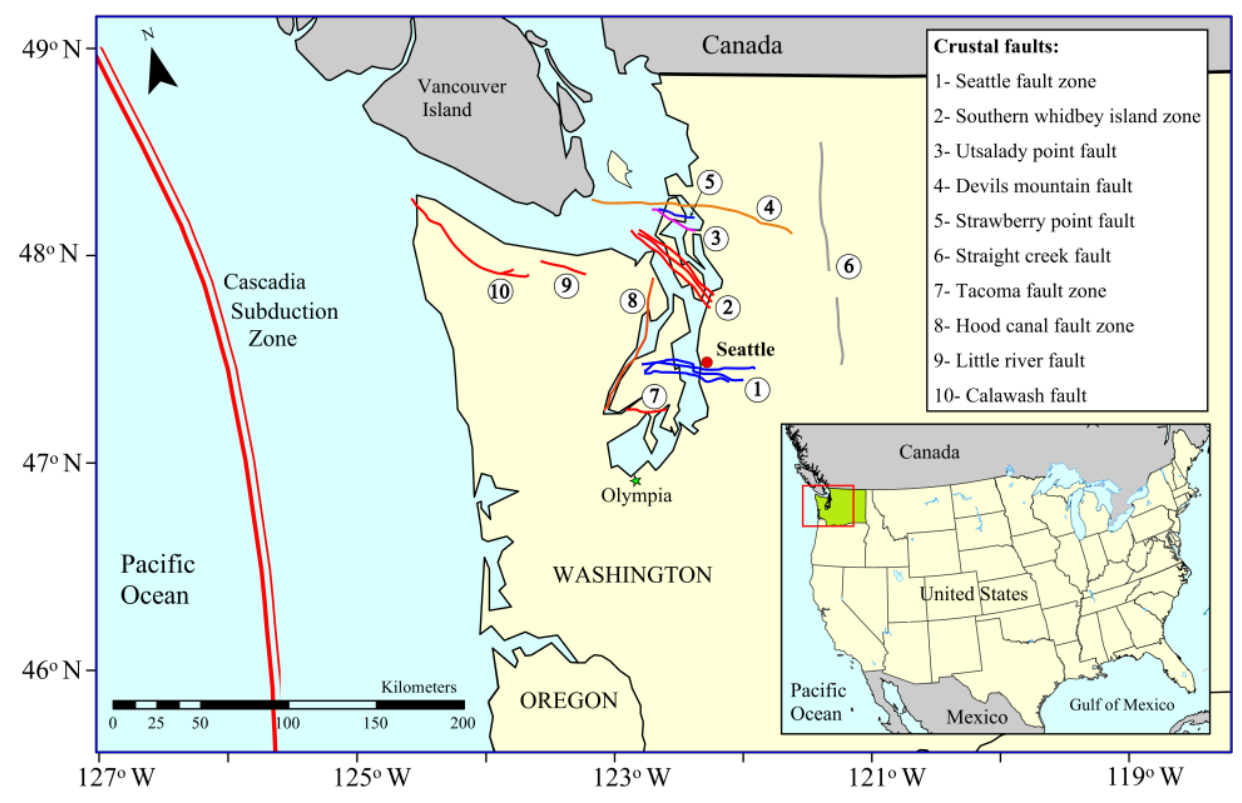

Fig. 5. Site location, crustal faults and Cascadia subduction zone.

\subsection{Site-specific seismic hazard information}

Using results of probabilistic seismic hazard analysis (PSHA) provided by the USGS (https://www.usgs.gov/), hazard curves that express the annual probability of exceeding various values of intensity measures $(I M)$ are extracted for the target site. Subsequently, a suite of ground motion records has been selected that is compatible with the selected hazard levels to be used in nonlinear dynamic analysis of the proposed structure. For the latter, earthquake scenarios based on seismic disaggregation can be used. Considering the complex seismicity of Seattle, which consists of different earthquake sources (crustal, inslab, and interface), multiple ground motion models (based on the USGS 2014 recommendation) for different scenarios are used in this paper.

The $I M$ selected for this study is the 5\% damped spectral acceleration response at the building's estimated first mode period $S_{a}(T 1)$ where $T 1$ is the first natural vibration period of the structure and equals 0.5 s. Due to the lack of locally recorded strong motion time-histories, ground motion data from other seismic regions are often required. To facilitate the record selection of appropriate MSAS sequences for seismic performance evaluation, real MSAS sequences that are constructed based on the PEER-NGA database for worldwide shallow crustal earthquakes [11] and the K-NET/KiK-net database for Japanese earthquakes [43] are integrated. MSAS sequences are referred to as real or as-recorded because no artificial method (such as randomized or back-toback records) is used in generating MSAS records. In a sequence of ground motions, the record with the highest moment magnitude is the mainshock record and all other records are from aftershocks. In this study, only one major aftershock record is selected. 172 and 531 sequences (each sequence consists of two horizontal components) are available from the PEER-NGA database and the K-NET/KiK-net database, respectively. The combined database is one of the most comprehensive datasets for as-recorded MSAS sequences and thus is suitable to conduct incremental dynamic analysis (IDA) [44]. Complete record information for both mainshocks and aftershocks can be found in the references mentioned above.

The uniform hazard spectrum (UHS) and the $2 \%$ probability of exceedance in 50 years (MCE) design spectrum for the site of interest are shown in Fig. 6(a). Fig. 6(b) shows site-specific hazard curves at different 
probabilities of exceedance for $S_{a}(T 1)$. The UHS is constructed by enveloping the spectral amplitudes at all different periods that are exceeded with $2 \%$ probability in 50 years, as computed from PSHA. PSHA also provides information about the earthquake events that are most likely to cause the occurrence of the target spectral amplitude at a given period. Knowing that the fundamental vibration period of the structure is $0.5 \mathrm{~s}$ and the annual frequency of exceedance of interest is $2 \%$ in 50 years, the $S_{a}(T 1)$ value is $1.381 \mathrm{~g}$. Fig. 7 shows the disaggregation distribution of magnitudes, distances, and their contributions to the site that will cause the occurrence of $S_{a}(T 1)=1.381 \mathrm{~g}$ at this site. The disaggregation information also shows three scenarios of events with different magnitudes and distances and their contributions to the specific site (Seattle). Therefore, when a single target response spectrum is constructed using the average values of magnitude and distance as suggested by the USGS, a significant bias may be caused in ground motion selection and consequently in seismic risk and performance assessment of the structure. To reduce the bias, a multi-scenario-based ground motion selection procedure is used by extending the single-scenario-based conditional mean spectrum (CMS) method proposed by Baker [45].

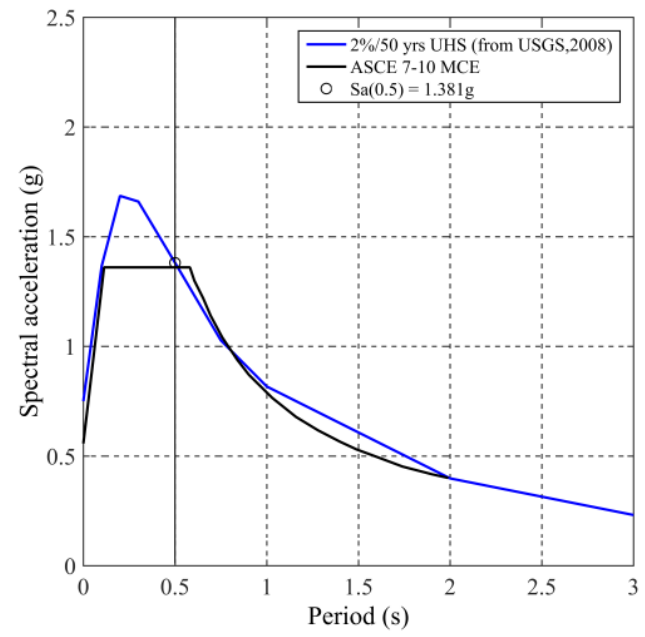

(a)



(b)

Fig. 6. (a) Uniform hazard spectrum and MCE design spectrum for Seattle and (b) site-specific hazard curve

In 2014, the USGS updated their PSHA model by changing ground motion prediction equations (GMPEs) and their weighting factors, which are listed in Table 1. Based on source, path and site parameters, GMPEs predict the median $S_{a}(T 1)$. Fig. 8(a) shows the UHS for Seattle with predicted median spectrum from the GMPEs, the average predicted median spectrum and $+\varepsilon \sigma$ spectrum associated with $\mathrm{M}=7.17, \mathrm{R}=3.8 \mathrm{~km}$, and $\varepsilon=0.9$ from multiple GMPEs for the crustal event. The $\varepsilon$ parameter is defined as the number of standard deviations by which the $\ln \left(S_{a}\right)$ value differs from the mean predicted $\ln \left(S_{a}\right)$ value for a given magnitude and distance. Among the GMPEs for crustal events, the Idriss model [46] is valid for $V_{s 30}$ greater than $450 \mathrm{~m} / \mathrm{s}$ only thus, it is not considered in this study. Fig. 8(b and c) shows the predicted median spectra from GMPEs, the average predicted median spectra and $+\varepsilon \sigma$ spectra, for inslab and interface earthquakes, respectively. Compared to crustal and inslab events, predicted median spectra for interface events have more variation, and due to its mechanism and distance they have richer spectral content in longer periods. Fig. 8(d) compares median $+\varepsilon \sigma$ spectra for the crustal, inslab and interface events. It shows that the interface events have much richer spectral content in the long vibration period range in comparison with the inslab events. 


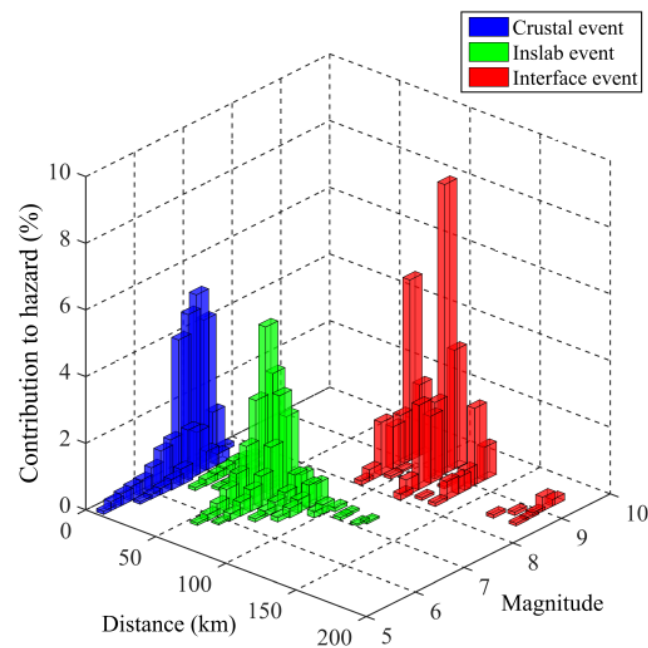

Fig. 7. PSHA disaggregation for Seattle with regard to magnitude, distance, and earthquake type

Table 1. Weight factors for crustal, inslab and interface ground motion prediction models based on the USGS 2104 recommendation

\begin{tabular}{lc}
\hline \multicolumn{1}{c}{ Ground Motion Prediction Model } & 2014 Weight \\
\cline { 1 - 2 } Idriss [46] & 0.12 \\
Boore at al. [47] & 0.22 \\
Campbell and Bozorgnia [48] & 0.22 \\
Chiou and Youngs [49] & 0.22 \\
Abrahamson et al. [60] & 0.22 \\
\hline \multicolumn{1}{c}{ Inslab } & 0 \\
\hline Geomatrix [51] & 0.1667 \\
Atkinson and Boore global model [52] & 0.1667 \\
Atkinson and Boore Cascadia model [52] & 0.33 \\
Zhao et al. [53] & 0.33 \\
BC Hydro [54] & \\
\hline \multicolumn{1}{c}{ Interface } & 0 \\
\hline Geomatrix [51] & 0.10 \\
Atkinson and Boore global model [52] & 0.30 \\
Zhao et al. [53] & 0.30 \\
BC Hydro [54] & 0.30 \\
Atkinson and Macias [55] & \\
\hline
\end{tabular}

\subsection{Ground motion selection}

After defining the event-based CMS (Fig. 8) for the specific location and structure of interest, ground motion sequences are selected for each event type (crustal, inslab, and interface). It is worth mentioning that even though the records are from Japanese earthquakes, influenced by seismotectonic and site characteristics in Japan, target CMS are defined based on the USGS PSHA information. Considering that the selected GMPEs together with weights are suitable for the Pacific Northwest, the selected records reflect regional seismicity and expected ground motions for Seattle and thus are adequate for use in IDA.

Once the initial selection of records is completed, records can be matched with the target CMS for each 
scenario. To identify ground motions matching with the target CMS, it is important to define a period range within which the response spectrum of a candidate record should be in close agreement with the CMS. This period range should include all periods to which the structural response is sensitive. ASCE 7-05 suggests using a period range from $0.2 T 1$ to $1.5 T 1$ for fixed-based structures. Past studies suggest that nonlinear systems are often sensitive to response spectra at periods longer than $1.5 T 1[56,57]$. Thus, the period range from $0.2 T 1$ to $2.0 T 1(0.1 \mathrm{~s}$ to $1.0 \mathrm{~s})$ is selected in this study. The next step is to scale each ground motion so that $S_{a}(T 1)$ of each record matches with $S_{a}(T 1)$ from the CMS. In other words, the scale factor is the ratio between the target $S_{a}(T 1)$ and the unscaled ground motion $S_{a}(T 1)$. The PEER-NGA records are scaled to match $S_{a}(T 1)$ of crustal CMS, and Japanese records are scaled to match $S_{a}(T 1)$ of inslab and interface CMS, respectively. Then, the errors between the target spectrum and scaled record spectrum can be calculated in the period range of interest. The metric used in this study to measure the error of each scaled record with the target CMS is the sum of squared errors (SSE) in logarithmic space.

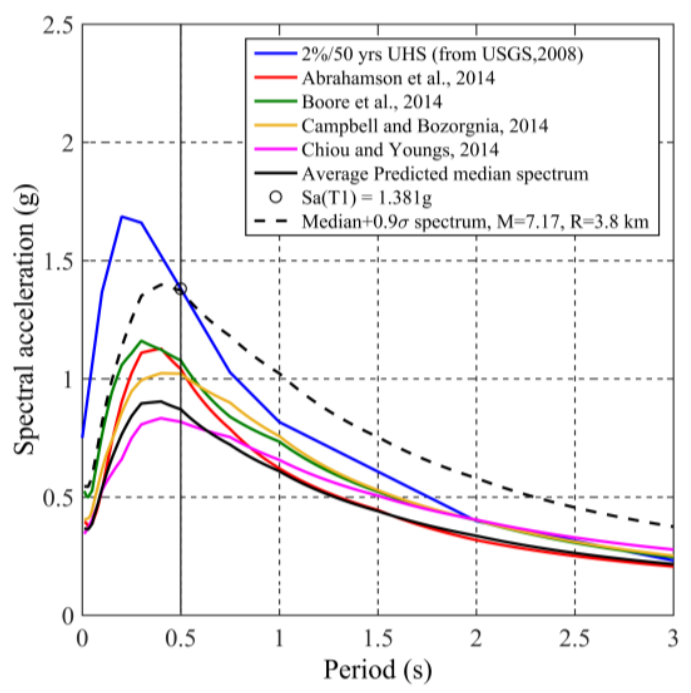

(a)



(c)

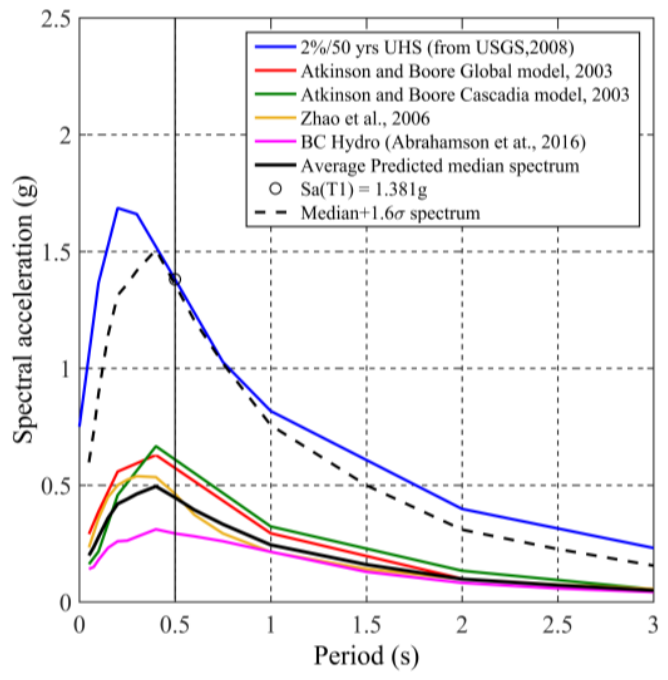

(b)

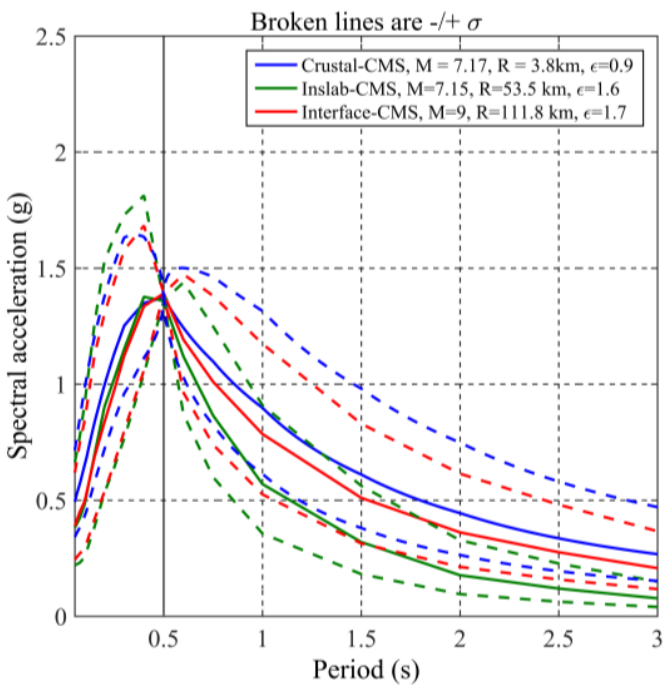

(d)

Fig. 8. Uniform hazard spectrum for Seattle with average predicted median spectrum (a) $+0.9 \sigma$ spectra associated with $\mathrm{M}=7.17$ and $\mathrm{R}=3.8 \mathrm{~km}$ from multiple crustal GMPEs, (b) $+1.6 \sigma$ spectra associated with $\mathrm{M}=7.15$ and $\mathrm{R}=53.5 \mathrm{~km}$ from multiple inslab GMPEs, (c) $+1.7 \sigma$ spectra associated with $\mathrm{M}=9$ and $\mathrm{R}=11.8 \mathrm{~km}$ from multiple interface GMPEs, (d) conditional mean spectra (median and median -/+ one standard deviation) for crustal, inslab and interface events. 
It is worth mentioning that the ground motion spectrum to calculate the SSE is the geometric mean of two horizontal components. The ground motion selection at this stage considers the scaling and the error simultaneously. Other researchers reported that using large-scale factors can induce a systematic bias in the median nonlinear structural response [58]. To reduce the bias in the computed nonlinear structural response and to have a sufficient number of records for each scenario, the error and scaling factor are constrained so that there are at least 20 components for each event type and the maximum acceptable scale factor is taken as 6 . To prevent any severe manipulations of the MSAS sequences, the scaling is implemented on the amplitude of the records alone. The frequency content and duration of records are not altered. Fig. 9 shows response spectra of the selected ground motion (geometric mean of two components) matched with the target $S_{a}(T 1)$. Details of the selected records, such as peak ground acceleration (PGA), Arias Intensity (AI), significant duration, and predominant period, are given in Appendix A.

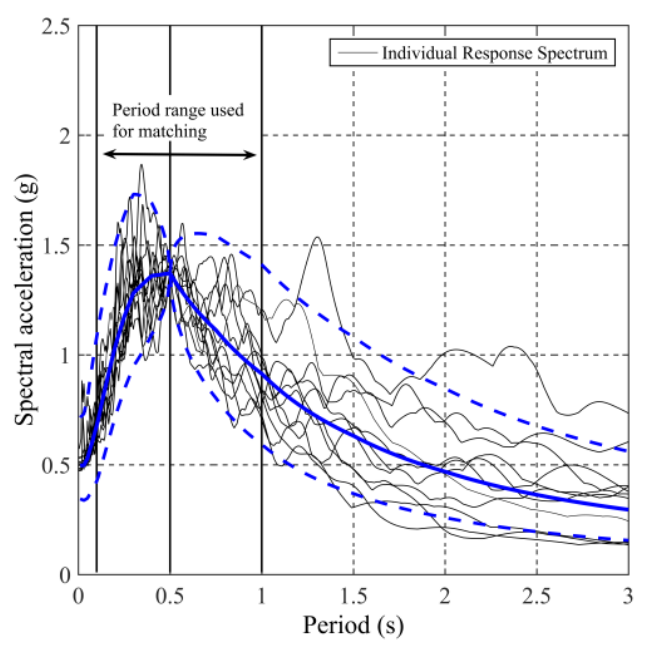

(a)

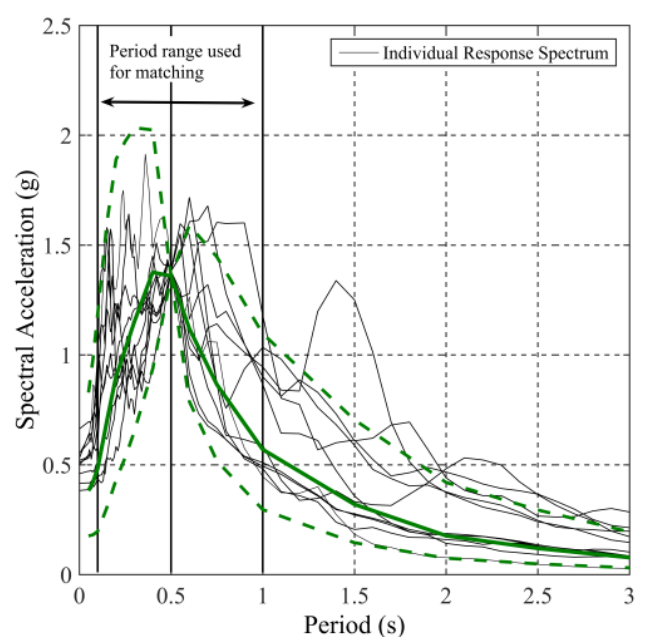

(b)

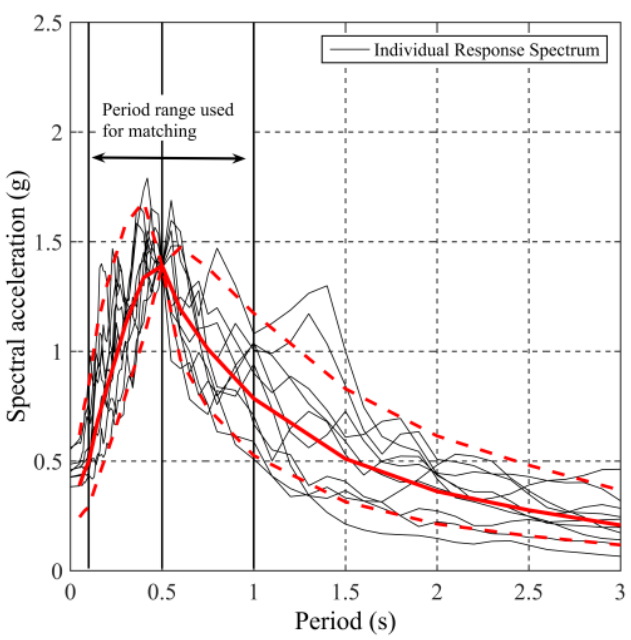

(c)

Fig. 9. Ground motions selected after scaling spectra and matching with the event-based CMS over the period range of interest (a) crustal, (b) inslab, and (c) interface events

\subsection{Development of fragility functions}

Developing fragility functions using nonlinear dynamic analysis of a structure is an important step in seismic vulnerability assessment procedures. There are many methods for performing nonlinear dynamic 
analysis of structures to obtain the data for developing a fragility function. A common approach is IDA which involves performing nonlinear dynamic analyses of a structural model using a set of ground motion records, each record scaled to multiple $I M$ levels [44]. An advantage of IDA is that it covers a wide range of IM, thus allowing simulation of structural behavior from initial elastic response to complete collapse. It also facilitates the quantification of uncertainty associated with the prediction. The MS fragility curves presented in this study are calculated by running IDA simulations and employing Eq (5). For MSAS fragility curves the same equation is used, but the input excitations consist of MS record followed by 60 seconds of zero acceleration and then AS. By implementing this approach, the structural systems excited by previous ground motion return to at-rest condition (but might have sustained damage). The following paragraphs provide the mathematical formulation on fragility functions. The fragility function is often defined as a lognormal cumulative distribution function:

$$
P(D S \geq d s \mid I M=x)=\Phi\left(\frac{\ln (x)-\ln (\theta)}{\beta}\right)
$$

where $P(D S \geq d s \mid I M=x)$ is the probability that a ground motion with $I M=x$ causes the structure to reach a specific damage state $d s$ or greater, $\Phi$ is the standard normal cumulative distribution function (CDF), $\theta$ and $\beta$ are the median and logarithmic standard deviation of the fragility function, respectively. There are different ways to calculate $\theta$ and $\beta$. The method adopted in this study is the moment estimator which is applicable to IDA.

$$
\begin{gathered}
\ln (\theta)=\frac{1}{n} \sum_{i=1}^{n} \ln \left(I M_{i}\right) \\
\beta=\sqrt{\frac{1}{n-1} \sum_{i=1}^{n}\left(\ln \left(I M_{i}\right)-\ln (\theta)\right)^{2}}
\end{gathered}
$$

where $n$ is the number of ground motions considered in the analysis, and $I M_{i}$ is the $I M$ value at the onset of the damage state for the $i$ th ground motion. Considering that $I M$ is lognormally distributed, the mean and median of $\ln (I M)$ coincide, which is the reason for using the sample mean in the estimation of $\theta$.

Another important criterion involved in $\operatorname{Eq}(5)$ is the selection of a damage index. Inter-story drift ratio (IDR) is selected in this study to highlight the fact that choosing the ductility-based index (maximum displacement) does not necessarily mean damage in seismic fragility and vulnerability assessment of structures. This is a critical decision especially when the aim is to compare different ground motion types, varying in duration and input energy. Damage in RC buildings generally starts with cracking and spalling of cover concrete. Following spalling of the cover concrete, fracture of longitudinal reinforcing bars due to large tensile strain and/or low-cycle fatigue, crushing of the core confined concrete and/or buckling of longitudinal bars in compression may lead the structure to collapse. In this paper, damage states are calculated based on lateral force-deformation as it is shown in Fig.4. Slight damage at $0.5 \%$ IDR is related to flexural or shear type hairline cracks in some beams and columns near joints or within joints. Moderate damage at $1 \%$ IDR corresponds to larger flexural cracks and some concrete spalling. Extensive damage at 3\% IDR is related to large flexural cracks, spalled concrete and rebar buckling in columns (elements have reached their ultimate capacity). Finally, complete damage means that the structure is collapsed or in imminent danger of collapse due to brittle failure of non-ductile frame elements or loss of frame stability. The advantage of the proposed structural model is that it captures responses (stress-strain responses) of concrete and reinforcement material considering all degradation processes due to concrete crushing and buckling and fatigue in the reinforcement. The objective is to highlight the advantage of the proposed model and its capabilities of capturing local and global responses of RC structures. The information from such a model can be used to define an advanced damage measure that can 
quantify damage more accurately.

\section{Results and discussion}

\subsection{Influence of ground motion characteristics on structural damage}

There are many studies reporting correlations between strong ground motion duration and structural damage [59-63]. However, these studies present different conclusions ranging from null to significant impact of ground motion duration. This discrepancy in the literature can be attributed to using different structural models, different sets of ground motions records, and different damage indices. Structural models exhibiting degradation of strength and/or stiffness under cyclic loading are more sensitive to the number of cycles of ground motion excitations [61]. For instance, studies that used the maximum drift or displacement, concluded that ground motion duration is statistically insignificant to maximum displacement of the structure [62]. On the other hand, studies using cumulative damage indices (cumulative energy or displacement) found a correlation between ground motion duration and structural damage $[59,60,63]$.

Before discussing the IDA results, it is important to present the characteristics of the MSAS records in this paper. Table 2 presents the average PGA, AI, energy density, predominant period and significant duration of crustal, inslab and interface MSAS selected records. The crustal and inslab have higher PGA for their MS compared to interface records. Another criterion that has a direct correlation with the induced damage is the released energy. The average energy density of crustal MS is 2 times and 7 times greater than interface and inslab records, respectively. This is due to shallow depth of crustal records, on the other hand for inslab and interface events, seismic waves scatter in broader area while propagating from source to site. Significant duration of record was investigated using $\mathrm{AI}$ ( $5 \%$ to $95 \%)$. The average AI of the selected interface MS records is higher (megathrust earthquake with a magnitude of 8 and 9) and follows by crustal events (shallow earthquake less than $10 \mathrm{~km}$ depth). The average significant duration, which is dominated by interface events is up to 4 times of the crustal events. Finally, the average predominant period, interface and inslab MS events have higher predominant period due to their different source/path mechanism (distance and depth). For the low-rise RC building, each of these different characteristics can result in different damage. For example, a high PGA of crustal events with energy released in a short period of time can generate significant lateral force, while a longduration interface event can damage structural elements due to low-cycle fatigue.

Table 2. Average acceleration, Arias Intensity, energy density, predominant period and significant duration of crustal, inslab and interface mainshock-aftershock record

\begin{tabular}{|c|c|c|c|c|c|c|}
\hline & \multicolumn{3}{|c|}{ Mainshock } & \multicolumn{3}{|c|}{ Aftershock } \\
\hline & Crustal & Inslab & Interface & Crustal & Inslab & Interface \\
\hline Acceleration $(\mathrm{g})$ & 0.52 & 0.54 & 0.44 & 0.29 & 0.33 & 0.35 \\
\hline Arias Intensity $(\mathrm{m} / \mathrm{s})$ & 7.33 & 5.22 & 12.91 & 1.46 & 1.92 & 3.78 \\
\hline Energy Density (m2/s) & 46906.4 & 5824.6 & 24937.9 & 3180.1 & 1880.9 & 4559.3 \\
\hline Period (s) & 0.43 & 0.48 & 0.53 & 0.36 & 0.40 & 0.40 \\
\hline Significant Duration (s) & 23.57 & 26.37 & 84.50 & 16.49 & 28.05 & 49.81 \\
\hline
\end{tabular}

Considering the different characteristics of each set of MSAS records that was explained in the previous section, Fig. 10 presents the median IDA results and fragility curves for different event types (crustal, inslab, and interface) based on the employed structural model. Damage limit states are based on maximum inter-story 
drift ratios (Table 2). The maximum inter-story drift ratios of $0.005,0.01,0.03$, and 0.05 which correspond to slight, moderate, extensive, and complete damage, respectively, are also shown on each graph. Comparison of the analysis results show that crustal records impose more damage and have a higher probability of collapse in comparison with inslab and interface records, whilst comparing the inslab and interface ground motions, the interface records are more damaging. The former is due to the sudden release of energy and high PGA in shallow crustal events, resulting in large plastic deformation at plastic hinge locations in beams and columns. This will then result in severe buckling of vertical reinforcement and concrete crushing in compression as well as fracture of reinforcing bars in tension in columns and beams. It is also evident that slight and moderate damage states are not affected by ground motion types, while the extensive and collapse states are significantly influenced by ground motion types. It is important to highlight the fact that results and conclusions presented in this section are only valid for the specific building model and the set of MSAS records used in this study. The purpose of this study is not to generalize the outcomes to other structural models or ground motion sets.

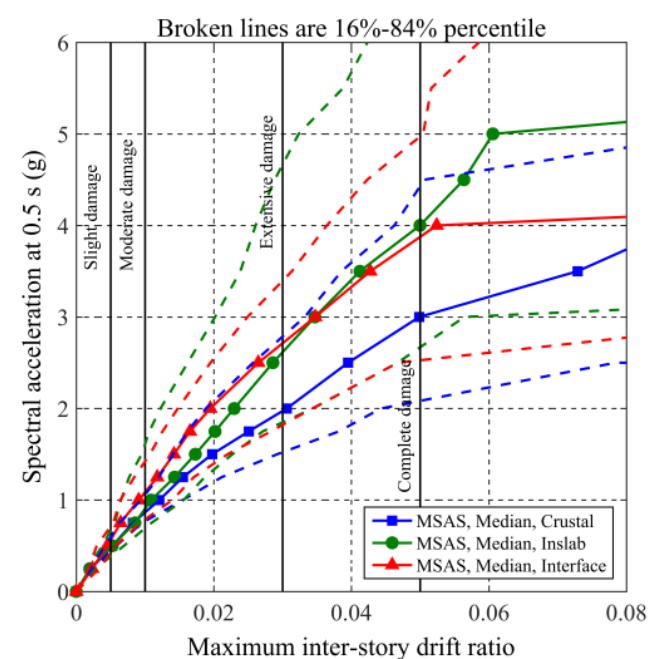

(a)



(b)

Fig. 10. (a) IDA and (b) fragility curves for crustal, inslab, and interface records by considering the buckling model subjected to the MSAS ground motions

Similarly, Iyama and Kuwamura [64] and Bommer et al. [65] reported that differences between subduction earthquakes and crustal earthquakes in terms of structural damage are due to the rapid release of energy. Fig. 10 also shows that interface records are more damaging in comparison with inslab records. This confirms that the greater number of cycles results in more fatigue degradation in the material (especially in reinforcement bars). The same conclusion was also drawn by De Matteis et al. [66]. Fig. 11 shows the fatigue damage index for the single element of the left-column at ground level. Once the fatigue damage index reaches 1.0, the stress/strain of the parent steel material is assumed to be zero (damage index of 1 due to fatigue means fracture of reinforcement). In the post-processing of the output data, an IDA simulation with fatigue damage index of 1 is categorized as complete damage and reflected in the fragility analysis. In general, aftershock slightly increases the fatigue damage index of longitudinal reinforcement due to the increased number of excitation cycles. The analysis results show that failure of reinforcement due to fatigue is more significant for interface MSAS ground motions, as it is shown in Fig. 11(c). It is worth mentioning that, even though drift ratio can predict the maximum response, it does not necessarily mean damage. In other words, using only structural peak 
deformation (i.e. drift) is not sufficient in seismic fragility and vulnerability assessment of structures. This is an important area for research as also mentioned by Mackie and Stojadinovic [67] and Freddi et al. [68, 69], and the proposed model developed in this paper can provide a platform for such investigations.



(a)



(b)

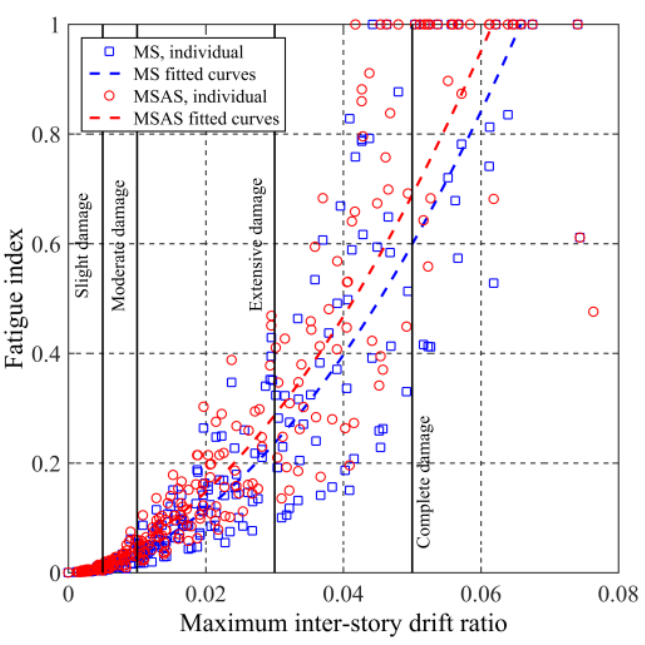

(c)

Fig. 11. Fatigue damage index for reinforcement (left-column at ground level) for the MS and MSAS cases:

(a) crustal records, (b) inslab records, and (c) interface records

\subsection{Aftershock impact}

As discussed before, aftershocks slightly increase the fatigue index of structural elements. However, it is important to investigate if aftershocks have enough energy to extend the damage or further to cause complete collapse. Fig. 12 shows the PGA, roof drift ratio, normalized AI, normalized energy flux (normalized with respect to the maximum interface AI and energy flux, respectively) and fatigue damage index for left-column at the ground level of three randomly selected crustal, inslab, and interface MSAS records. They are all scaled based on their MS to have $S_{a}(T 1)=1.5 \mathrm{~g}$. The crustal event has higher PGA with a rapid release of energy and consequently higher peak roof drift ratio. On the other hand, the interface event produces more energy over a longer duration, consequently, low-cycle fatigue has a dominant impact on the structural elements. Even though the fatigue damage index is not reaching 1 for these three selected records, it shows the potential damage mechanism of interface ground motions in comparison to crustal and inslab events. It is worth noting that in 
some specific cases (i.e. Crustal even, Fig 9a), the AS acceleration can be higher than the MS counterpart [one for crustal, two for inslab, and four for interface evens (see Table A1)]. This is because the fault rupture of the AS is closer to the site in comparison to that of the mainshock. To explore the effect of AS in more detail, Fig. 13 shows the hysteresis response of crustal, inslab and interface MSAS (normalized base shear versus roof drift ratio). The AS is shown with a dotted line in black and base shear is normalized by structure's weight. It can be seen that in the selected records, the crustal AS imposes more lateral deformation while the responses for inslab and interface records are more pinched.



(a)

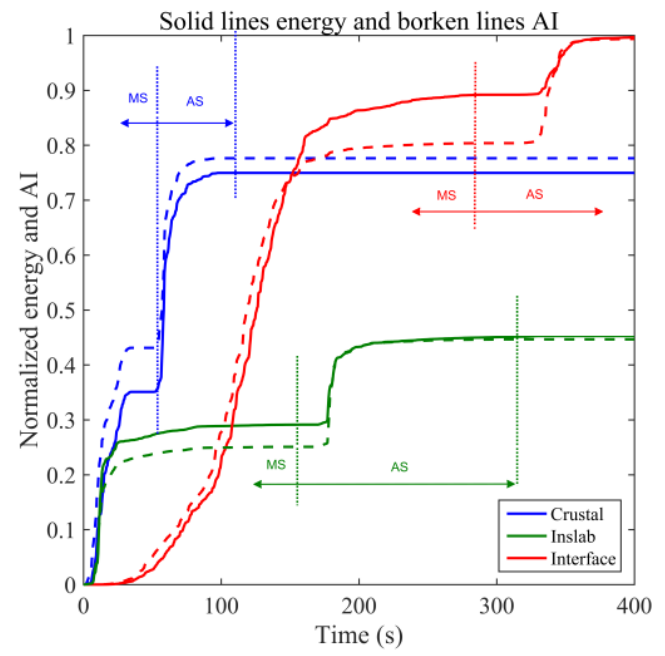

(c)



(b)



(d)

Fig. 12. Time-history data for (a) acceleration, (b) roof drift ratio, (c) normalized energy flux/AI and (d) fatigue index for the left-ground level column of crustal, inslab and interface MSAS 




(a)

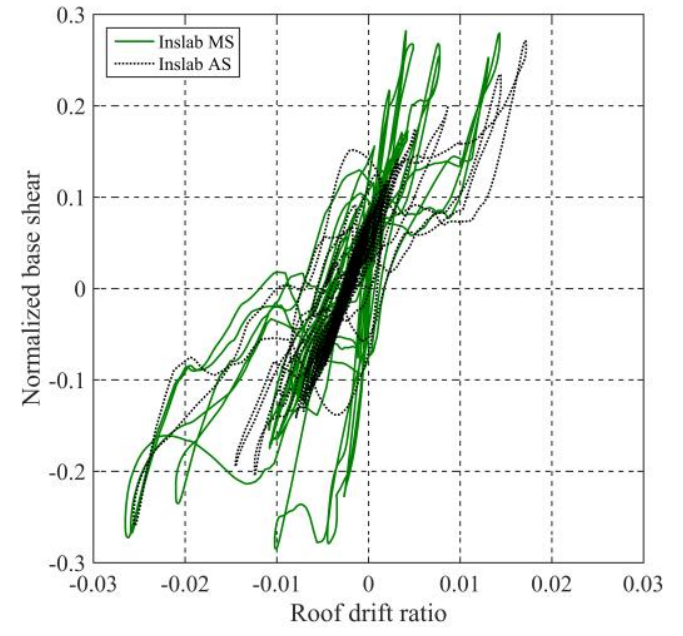

(b)

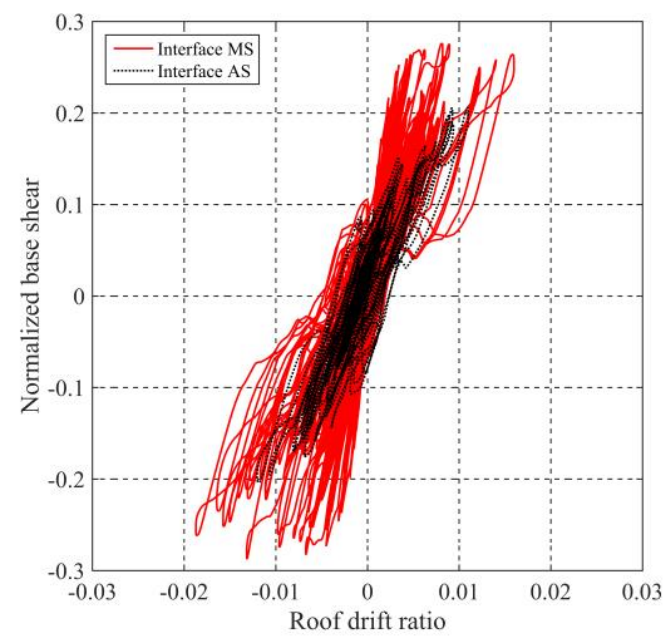

(c)

Fig. 13. Roof drift ratio and normalized base shear (normalized to structure weight) for (a) crustal, (b) inslab and (c) interface MSAS

To investigate the performance of the low-rise RC building for all different earthquake types, Fig. 14 shows the median IDA and corresponding fragility curves for the model including the bar buckling and fatigue effects due to the for MS and MSAS records. The analysis results show that considering aftershocks does not have a significant impact on the structural damage at slight and moderate limit states in all three event types for this specific structure/site. However, it increases the damage for extensive and complete damage limit states by about $10 \%$ for crustal events and 5\% for inslab events especially at spectral acceleration between 1.5 to $4.0 \mathrm{~g}$ (no additional damage for interface events). 




(a)



(c)

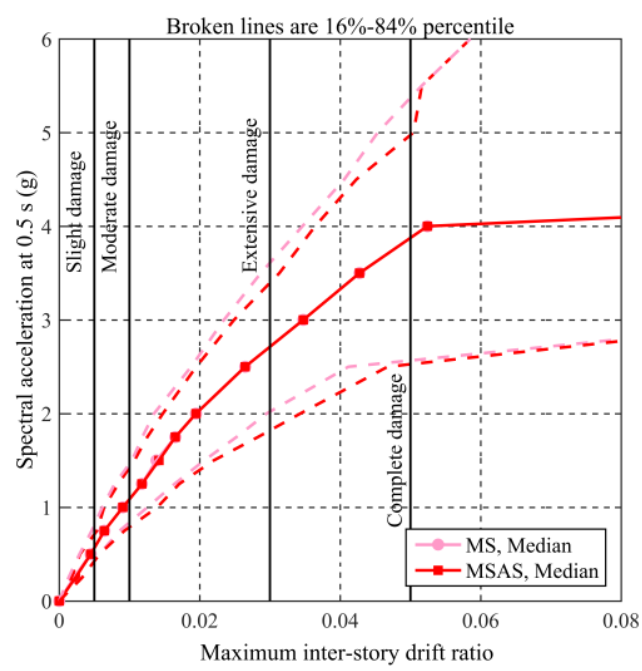

(e)



(b)

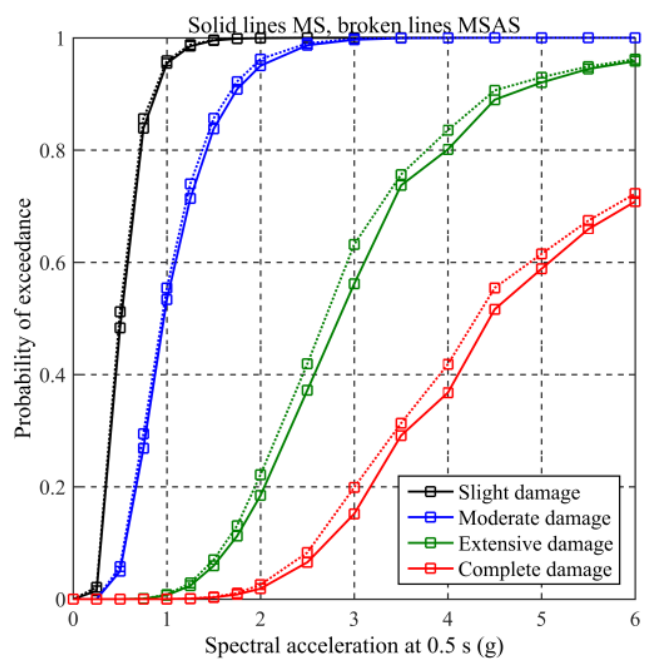

(d)

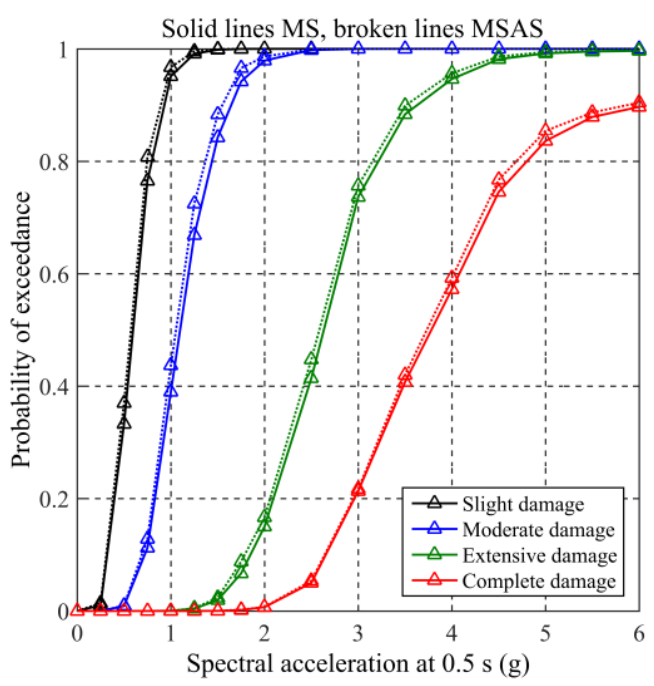

(f)

Fig. 14. IDA and fragility curves for the buckling-fatigue model by considering the MS and MSAS cases: (a and b) crustal records, (c and d) inslab records, and (e and f) interface records 


\subsection{Influence of structural modeling technique}

The final section presents the advantages of the developed fiber model over conventional fiber models (no buckling no low-cycle fatigue). It is a well-known fact that modeling techniques have a significant impact on nonlinear structural response and subsequently seismic risk assessment. Inelastic buckling and low-cycle fatigue degradation of longitudinal reinforcement in RC structures significantly influence the nonlinear structural response against earthquake loading. Fig. 15 shows the median IDA results with corresponding fragility curves for the structural model (shown in Fig. 1) with and without considering longitudinal reinforcement buckling and fatigue degradation.

Results are presented for MSAS sequences of three different events i.e., crustal, inslab, and interface. The results show that the fiber model including buckling and fatigue degradation increases the probability of collapse significantly for inslab and interface events. However, no significant change can be seen in slight, moderate and extensive damage limit states for inslab and interface events (at the lower drift of the structure). In other words, neglecting in-cycle degradation during numerical modeling hampers the model's ability to predict dynamic instability of the structure (collapse). One of the advantages of the proposed modeling technique is improving the structural analysis using fiber models which can capture different failure mechanisms (except for shear failure in the current version) under different ground motion types. Moreover, the proposed model can be used to develop an advanced damage index which integrates local (material response at each element) and global response (structural deformation) to quantify structural damage accurately, which is a goal for future research. 


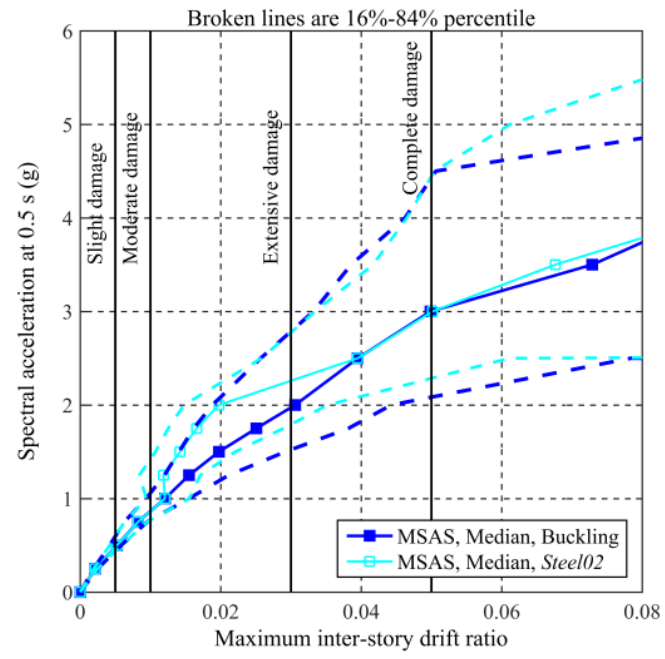

(a)

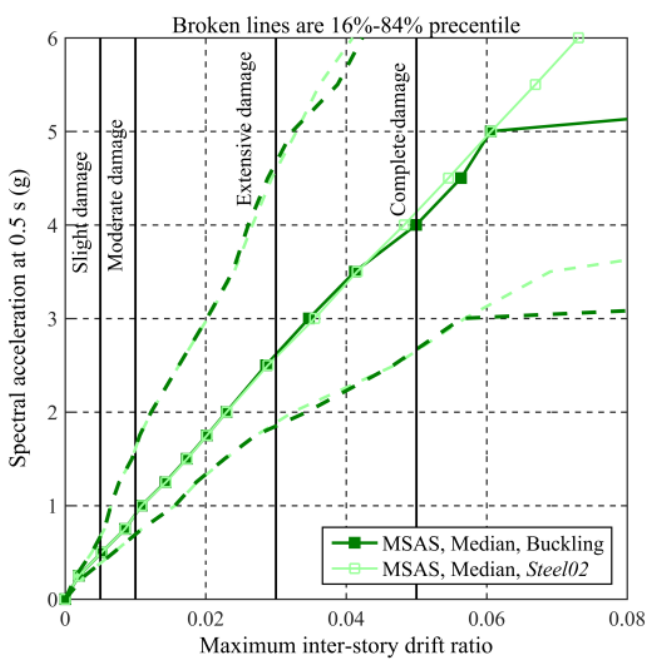

(c)

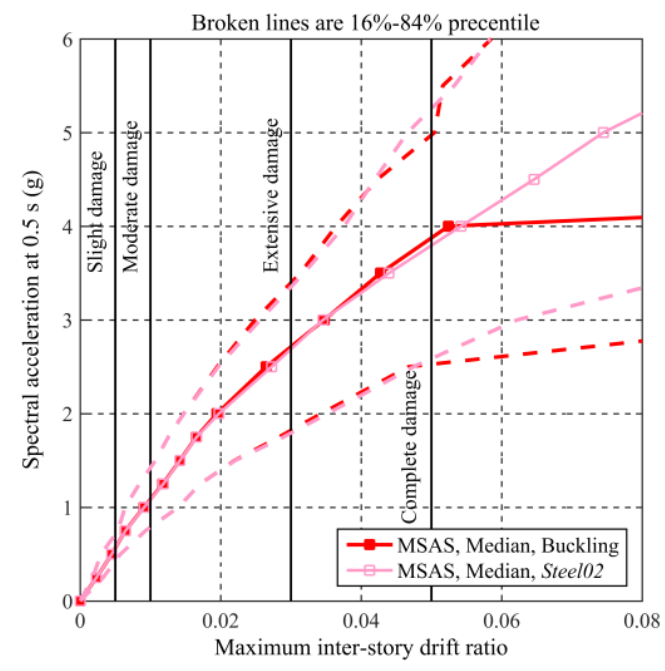

(e)



(b)



(d)



(f)

Fig. 15. IDA and fragility curves for the Steel02 and buckling-fatigue models by considering the MSAS case:(a and b) crustal records, (c and d) inslab records, and (e and f) interface records 


\section{Conclusions}

The advanced modeling technique using nonlinear fiber beam-column element is developed for RC frames. The model is used for seismic performance assessment of a prototype 2-story RC framed structure considering real MSAS sequences. The proposed model accounts for inelastic buckling and low-cycle fatigue degradation of longitudinal reinforcement under repeated cyclic loading, fracture of longitudinal bars in tension, and core confined concrete crushing in compression. The model presented in this paper can capture the cyclic degradation of RC components and simulate multiple failure modes. A rigorous ground motion selection is performed with a specific consideration of regional seismicity and site location in Seattle, US. Multiple event types are used to consider the variability of ground motions (crustal, inslab, and interface), and selected records consist of mainshock records and major aftershock records.

The main conclusions of this paper can be summarized as follows:

1) Considering rebar buckling and low-cycle fatigue in a fiber-type model increases the probability of collapse and consequently improve the accuracy of risk and vulnerability assessments of RC buildings.

2) For crustal ground motions, considering aftershocks increases the probability of exceedance of damage by about $10 \%$ for extensive and complete damage, while for inslab and interface records, the damage is increased by about $5 \%$. Slight and moderate damage is not affected by major aftershocks.

3) It is found that released energy, duration and PGA are important parameters of ground motions characteristics, which have a major influence on the structural damage and the damage mechanics by each property is different. It is shown that, for the specific structure considered in this study, structural damage for crustal events is due to excessive lateral deformation of the structure (peak response) caused by their high PGA, while for interface events damage is related to the long duration of excitation (number of cycles and fatigue).

4) Analysis results show that considering ductility-based (peak deformation) damage measures, i.e. drift, is not sufficient for fragility analysis of RC structures. An important area for future research is to develop a cumulative damage index which combines deformation and cumulative energy dissipation based on the local deformations (component rotations/curvature, shear deformation, and reinforcement slippage) as well as global structural system (drift). Such an index will incorporate the structural peak deformation, effects of ground motion duration, number of cycles, and influence of cyclic degradation on structural performance.

It is important to clarify that the results and conclusions presented in this paper are only valid for the specific building model and the set of MSAS records used in this study. Furthermore, the findings in this paper are only related to seismically designed modern buildings. It is expected that the impact of aftershocks or ground motion types for non-seismically designed building to be different, which is a topic of future research. The modeling technique presented in this paper can be used as a platform in future research to extensively investigate the impact of MSAS sequences for different ground motion types and structural details.

\section{Acknowledgments}

This work was supported by the Engineering and Physical Sciences Research Council (EP/M001067/1). Strong ground-motion data were obtained from the PEER-NGA database at (http://peer.berkeley.edu/nga/), the K-NET at (www.k-net.bosai.go.jp), and the KiK-net at (www.kik.bosai.go.jp). 


\section{References}

1. Rosenblueth E, Meli R. The 1985 Mexico earthquake: causes and effects in Mexico City. Concrete International 1986; 8(5): 23-34.

2. Ruiz-garcía J, Terán-gilmore A, Díaz G. Response of Essential Facilities Under Narrow-Band Mainshock-Aftershock Seismic Sequences. Proc. of 15th World Conference on Earthquake Engineering, Lisbon Portugal, 2012.

3. Smyrou E, Tasiopoulou P, Bal IE, Gazetas G, Vintzileou E. Ground motions versus geotechnical and structural damage in the February 2011 Christchurch earthquake. Seismological Research Letters 2011; 82(6): 882-892. DOI: $10.1785 / g s s r l .82 .6 .882$

4. Goda K, Pomonis A, Chian SC, Offord M, Saito K, Sammonds P, Fraser S. Ground motion characteristics and shaking damage of the 11th March 2011 Mw9.0 Great East Japan earthquake. Bulletin of Earthquake Engineering 2013; 11(1): 141-170. https://doi.org/10.1007/s10518-012-9371-X

5. Mahin SA. Effects of duration and aftershocks on inelastic design earthquakes. Proc. of 7th World Conference on Earthquake Engineering, Istanbul, Turkey, 1980.

6. Amadio C, Fragiacomo M, Rajgelj S. The effects of repeated earthquake ground motions on the nonlinear response of SDOF systems. Earthquake Engineering and Structural Dynamic 2003; 32(2): 291-308. DOI: 10.1002 /eqe. 225

7. Luco N, Bazzurro P, Cornell CA. Dynamic versus static computation of the residual capacity of a mainshock-damaged building to withstand an aftershock. Proc. of the 13th World Conference on Earthquake Engineering, Vancouver, Canada, 2004.

8. Hatzigeorgiou GD, Beskos DE. Inelastic displacement ratios for SDOF structures subjected to repeated earthquakes. Engineering Structures 2009; 31(11): 2744-2755. https://doi.org/10.1016/j.engstruct.2009.07.002

9. Hatzigeorgiou GD. Ductility demand spectra for multiple near- and far-fault earthquakes. Soil Dynamics and Earthquake Engineering 2010; 30(4): 170-183. https://doi.org/10.1016/j.soildyn.2009.10.003

10. Iervolino I, Giorgio M, Chioccarelli E. (2013) "Closed-form aftershock reliability of damage cumulating elastic-perfectly-plastic systems.” Earthquake Engineering and Structural Dynamics, 43(4): 613-625. DOI: 10.1002/eqe. 2363

11. Goda K, Taylor CA. Effects of aftershocks on peak ductility demand due to strong ground motion records from shallow crustal earthquakes. Earthquake Engineering and Structural Dynamics 2012; 41 (15): 2311-2330. DOI: 10.1002/eqe.2188

12. Fragiacomo M, Amadio C, Macorini L. Seismic response of steel frames under repeated earthquake $\begin{array}{lllll}\text { ground } & \text { motions. } & \text { Engineering } & \text { Structures } & 2021-2035 .\end{array}$ https://doi.org/10.1016/j.engstruct.2004.08.005

13. Lee K, Foutch DA. Performance evaluation of damaged steel frame buildings subjected to seismic loads. Journal of Structural Engineering 2004; 130(4): 588-599. https://doi.org/10.1061/(ASCE)07339445(2004)130:4(588)

14. Li Q, Ellingwood BR. Performance evaluation and damage assessment of steel frame buildings under mainshock-aftershock earthquake sequences. Earthquake Engineering and Structural Dynamics 2007; 36(3): 405-427. DOI: 10.1002/eqe.667

15. Hatzigeorgiou GD, Liolios A. Nonlinear behavior of RC frames under repeated strong ground motions. 
Soil Dynamics and Earthquake Engineering 2010; $\quad 30(10)$ 1010-1025.

https://doi.org/10.1016/j.soildyn.2010.04.013

16. Faisal A, Majid Ta, Hatzigeorgiou GD. Investigation of story ductility demands of inelastic concrete frames subjected to repeated earthquakes. Soil Dynamics and Earthquake Engineering 2013; 44(1): 42-53. DOI: 10.1016/j.soildyn.2012.08.012

17. Di Sarno L. Effects of multiple earthquakes on inelastic structural response. Engineering Structures 2013; 56(10): 673-681. https://doi.org/10.1016/j.engstruct.2013.05.041

18. Ebrahimian H. A performance-based framework for adaptive seismic aftershock risk assessment. Earthquake Engineering and Structural Dynamics 2014; 43(14): 2179-2197. DOI: 10.1002/eqe.2444

19. Goda K, Tesfamariam S. Seismic Risk Management of Existing Reinforced Concrete Buildings in the Cascadia Subduction Zone. Natural Hazards Review 2015; 18 (1): 1-10. DOI: 10.1061/(ASCE)NH.1527$\underline{6996.0000206}$

20. Abdelnaby AE, Elnashai AS. Numerical modeling and analysis of RC frames subjected to multiple earthquakes. Earthquakes and Structures 2015; 9(5): 957-981.

DOI: http://dx.doi.org/10.12989/eas.2015.9.5.957

21. Hosseinpour F, Abdelnaby AE. Fragility curves for RC frames under multiple earthquakes. Soil Dynamics and Earthquake Engineering 2017; 98: 222-234. https://doi.org/10.1016/j.soildyn.2017.04.013

22. Raghunandan M, Liel AB, Luco N. Aftershock collapse vulnerability assessment of reinforced concrete frame structures. Earthquake Engineering and Structural Dynamics 2015; 44(3): 419-439. DOI: $10.1002 /$ eqe. 2478

23. Jeon JS, DesRoches R, Lowes LN, Brilakis I. Framework of aftershock fragility assessment-case studies: older California reinforced concrete building frames. Earthquake Engineering and Structural Dynamics 2015; 44(15): 2617-2636. DOI: 10.1002/eqe.2599

24. Haselton CB. Assessing seismic collapse safety of modern reinforced concrete moment frame buildings. $\mathrm{PhD}$ Thesis, Department of Civil and Environmental Engineering, Stanford University, 2006.

25. ICC. International building code 2003. International Code Council, 2003.

26. ASCE-7. Minimum design loads for buildings and other structures. Structural Engineering Institute, 2002.

27. ACI. Building code requirements for structural concrete." ACI 318-02, American Concrete Institute, Farmington Hills, MI, 2002.

28. Kashani MM, Lowes LN, Crewe AJ, Alexander NA. Nonlinear fibre element modelling of RC bridge piers considering inelastic buckling of reinforcement. Engineering Structures, 2016; 116: 163-177. https://doi.org/10.1016/j.engstruct.2016.02.051

29. Kashani MM, Lowes LN, Crewe AJ, Alexander NA. Phenomenological hysteretic model for corroded reinforcing bars including inelastic buckling and low-cycle fatigue degradation. Computers and Structures 2015; 156: 58-71. https://doi.org/10.1016/j.compstruc.2015.04.005

30. Kashani MM, Barmi AK, Malinova VS. Influence of inelastic buckling on low-cycle fatigue degradation of reinforcing bars. Construction and Building Materials, 2015; 94: 644-655. https://doi.org/10.1016/j.conbuildmat.2015.07.102

31. Kashani MM, Salami MR, Goda K, Alexander NA. Nonlinear flexural behaviour of RC columns 
including bar buckling and fatigue degradation. Magazine of Concrete Research 2017; 70: 231-247 http://dx.doi.org/10.1680/jmacr.16.00495

32. McKenna F, Fenves GL, Scott MH. OpenSees: Open system for earthquake engineering simulation. Pacific Earthquake Engineering Research Center, University of California, Berkeley, California, 2006.

33. Dhakal RP, Maekawa K. Reinforcement stability and fracture of cover concrete in reinforced concrete members. Journal of Structural Engineering 2002; 128(10):1253-62.

34. Berry MP, Eberhard MO. Performance modeling strategies for modern reinforced concrete bridge columns." Berkeley, Pacific Earthquake Engineering Research Centre, 2006.

35. Menegotto M, and Pinto PE. Method of analysis of cyclically loaded RC plane frames including changes in geometry and nonelastic behavior of elements under normal force and bending. In Preliminary Report, 13:15-22. Zurich: IABSE, 1973.

36. Filippou FC, Popov EP, Bertero VV. Effects of bond deterioration on hysteretic behavior of reinforced concrete joints. University of California, Berkeley, 1983.

37. Bauschinger J. Variations in the elastic limit of iron and steel. The Journal of the Iron and Steel Institute 1887; 12(1): 442-444.

38. Ballio G, Castiglioni C A. A Unified Approach for the Design of Steel Structures under Low and/or High Cycle Fatigue. Journal of Constructional Steel Research 1995; 34: 75-1

39. Park R, Priestley N, Gill W. Ductility of square-confined concrete columns. Journal of the Structural Division 1982; 108(4): 929-950.

40. Mander JB, Priestley MJN, Park R. Theoretical stress-strain model for confined concrete. Journal of Structural Engineering 1988; 114(8): 1804-1825. https://doi.org/10.1061/(ASCE)0733-9445(1988)114:8(1804)

41. Mazzotti S, Dragert H, Hyndman RD, Miller MM, Henton JA. GPS deformation in a region of high crustal seismicity: N. Cascadia Forearc. Earth and Planetary Science Letters 2002; 198(1-2): 41-48. https://doi.org/10.1016/S0012-821X(02)00520-4

42. Weaver CS, Baker GE. Geometry of the Juan de Fuca plate beneath Washington and northern Oregon from seismicity. Bulletin of the Seismological Society of America 1988; 78(1): 264-275.

43. Goda K, Wenzel F, De Risi R. Empirical Assessment of Non-Linear Seismic Demand of MainshockAftershock Ground-Motion Sequences for Japanese Earthquakes. Frontiers in Built Environment 2015; 1(6): 117. DOI: $10.3389 /$ fbuil.2015.00006

44. Vamvatsikos D, Cornell CA. Incremental dynamic analysis. Earthquake Engineering and Structural Dynamics 2002; 31(3): 491-514. DOI: 10.1002/eqe.141

45. Baker J. Conditional mean spectrum: Tool for ground-motion selection. Journal of Structural Engineering 2011; 137(3): 322-331. https://doi.org/10.1061/(ASCE)ST.1943-541X.0000215

46. Idriss IM. NGA-West2 model for estimating average horizontal values of pseudo-absolute spectral accelerations generated by crustal earthquakes. University of California, Berkeley, Pacific Earthquake Engineering Research Center PEER Report, 2013.

47. Boore DM, Stewart JP, Seyhan E, Atkinson GA. NGA-West2 equations for predicting response spectral accelerations for shallow crustal earthquakes. University of California, Berkeley, Pacific Earthquake Engineering Research Center PEER Report, 2013.

48. Campbell KW, Bozorgnia Y. NGA-West2 Campbell-Bozorgnia Ground Motion Model for the 
horizontal components of PGA, PGV, and 5\%-damped elastic pseudo acceleration response spectra for periods ranging from 0.01 to $10 \mathrm{~s}$. University of California, Berkeley, Pacific Earthquake Engineering Research Center PEER Report, 2013.

49. Chiou BSJ, Youngs RR. Update of the Chiou and Youngs NGA ground motion model for average horizontal component of peak ground motion and response spectra. University of California, Berkeley, Pacific Earthquake Engineering Research Center PEER Report, 2013.

50. Abrahamson NA, Silva WJ, Kamai R. Summary of the ASK14 Ground Motion Relation for Active Crustal Regions. Earthquake Spectra 2014; 30(3): 1025-1055. https://doi.org/10.1193/070913EQS198M

51. Youngs RR, Chiou SJ, Silva WJ, Humphrey JR. Strong ground motion attenuation relationships for subduction zone earthquakes." Seismological Research Letters 1997; 68(1): 58-73. DOI: 10.1785/gssrl.68.1.58

52. Atkinson GM, Boore DM. Empirical ground-motion relations for subduction zone earthquakes and their application to Cascadia and other regions. Bulletin of the Seismological Society of America 2003; 93(4): 17031729. DOI: $10.1785 / 0120020156$

53. Zhao JX. Attenuation relations of strong ground motion in Japan using site classification based on predominant period. Bulletin of the Seismological Society of America 2006; 96(3): 898-913. DOI: $\underline{10.1785 / 0120050122}$

54. Abrahamson N, Gregor N, Addo K. BC Hydro Ground Motion Prediction Equations For Subduction Earthquakes. Earthquake Spectra 2016; 32(1): 23-44. https://doi.org/10.1193/051712EQS188MR

55. Atkinson GM, Macias M. Predicted ground motions for great interface earthquakes in the Cascadia subduction zone. Bulletin of the Seismological Society of America 2009; 99(3): 1552-1578. DOI: 10.1785/0120080147

56. Vamvatsikos D, Cornell CA. Developing efficient scalar and vector intensity measures for IDA capacity estimation by incorporating elastic spectral shape information. Earthquake Engineering and Structural Dynamics 2005; 34(13): 1573-1600. DOI: 10.1002/eqe.496

57. Baker JW, Cornell CA. Vector-valued Intensity Measures Incorporating Spectral Shape For Prediction of Structural Response. Journal of Earthquake Engineering 2008; 12(4): 534-554. DOI: 10.1080/13632460701673076.

58. Luco N, Bazzurro P. Does amplitude scaling of ground motion records result in biased nonlinear structural drift responses? Earthquake Engineering and Structural Dynamics 2007; 36(13): 1813-1835. DOI: $\underline{10.1002 / \text { eqe. } 695}$

59. Chandramohan R, Baker JW, Deierlein GG. Quantifying the influence of ground motion duration on structural collapse capacity using spectrally equivalent records. Earthquake Spectra 2013; 32(2): 927-950. https://doi.org/10.1193/122813EQS298MR2

60. Iervolino I, Giorgio M., Chioccarelli, E. Closed-form aftershock reliability of damage-cumulating elastic-perfectly-plastic systems. Earthquake Engineering and Structural Dynamics 2013; 43(4): 613-625. DOI:10.1002/eqe. 2363

61. Hancock J, Bommer JJ. A state-of-knowledge review of the influence of strong-motion duration on structural damage. Earthquake Spectra 2006; 22(3): 827-845. https://doi.org/10.1193/1.2220576

62. Iervolino I, Manfredi G. Cosenza E. Ground motion duration effects on nonlinear seismic response. Earthquake Engineering and Structural Dynamics 2006; 35(1): 21-38. DOI: 10.1002/eqe.529 
63. Raghunandan M, Liel AB. Effect of ground motion duration on earthquake induced structural collapse. Structural Safety 2013; 41(3): 119-133. DOI: 10.1016/j.strusafe.2012.12.002

64. Iyama J, Kuwamura H. Application of wavelets to analysis and simulation of earthquake motions. Earthquake Engineering and Structural Dynamics 1999; 28(3): 255-272. DOI: 10.1002/(SICI)10969845(199903)28:3<255::AID-EQE815>3.0.CO;2-C

65. Bommer JJ, Udias A, Cepeda JM, Hasbun JC, Salazar WM, Suarez A, Ambraseys NN,Buforn E, Cortina J, Madariaga R, Mendez P, Menzcua J, Papastamatiou D. A new digital accelerograph network for El Salvador. Seismological Research Letters 1997; 68(3): 426-436.

66. De Matteis G, Landolfo R, Calado L. Cyclic behaviour of semi-rigid angle connections: A comparative study of tests and modeling. Proc. of the $3^{\text {rd }}$ International Conference of Steel Structures in Seismic Area Behaviour, STESSA 2000, Montreal, Canada.

67. Mackie K, Stojadinovic B. Seismic demands for performance-based design of bridges. PEER Report No. 2003/13, Berkeley, CA.

68. Freddi F, Tubaldi E, Ragni L, Dall'Asta A. Probabilistic performance assessment of low-ductility reinforced concrete frame retrofitted with dissipative braces. Earthquake Engineering \& Structural Dynamic 2013; 42:993-1011.

69. Freddi F, Padgett J.E, Dall'Asta A. Probabilistic seismic demand modeling of local level response parameters of an RC frame. Bull Earthquake Engineering 2016; 15:1-23.

\section{Appendix A}

Table A1. Crustal mainshock-aftershock record information

\begin{tabular}{|c|c|c|c|c|c|c|c|c|}
\hline \multirow{2}{*}{$\begin{array}{l}\text { Sequence } \\
\text { Number }\end{array}$} & \multicolumn{4}{|c|}{ Mainshock } & \multicolumn{4}{|c|}{ Major Aftershock } \\
\hline & PGA(g) & $\mathrm{AI}(\mathrm{m} / \mathrm{s})$ & Period (s) & Duration (s) & PGA(g) & $\mathrm{AI}(\mathrm{m} / \mathrm{s})$ & Period (s) & Duration (s) \\
\hline 1 & 0.599 & 6.724 & 0.460 & 24.190 & 0.454 & 3.608 & 0.380 & 20.480 \\
\hline 2 & 0.520 & 5.452 & 0.460 & 26.090 & 0.448 & 3.440 & 0.380 & 21.735 \\
\hline 3 & 0.430 & 6.123 & 0.480 & 23.340 & 0.578 & 4.905 & 1.160 & 19.010 \\
\hline 4 & 0.495 & 6.502 & 0.320 & 24.230 & 0.465 & 4.250 & 0.420 & 20.040 \\
\hline 5 & 0.524 & 4.812 & 0.320 & 10.100 & 0.265 & 0.461 & 0.300 & 7.750 \\
\hline 6 & 0.504 & 2.398 & 0.500 & 9.840 & 0.265 & 0.296 & 0.320 & 7.510 \\
\hline 7 & 0.806 & 5.468 & 0.260 & 9.060 & 0.196 & 0.270 & 0.420 & 8.440 \\
\hline 8 & 0.537 & 3.394 & 0.540 & 8.260 & 0.124 & 0.160 & 0.460 & 9.705 \\
\hline 9 & 0.547 & 3.76 & 0.280 & 8.670 & 0.118 & 0.155 & 0.220 & 11.975 \\
\hline 10 & 0.600 & 3.16 & 0.280 & 5.805 & 0.111 & 0.152 & 0.220 & 9.965 \\
\hline 11 & 0.474 & 17.404 & 0.300 & 44.280 & 0.371 & 3.010 & 0.340 & 29.025 \\
\hline 12 & 0.438 & 13.181 & 0.460 & 44.940 & 0.338 & 1.947 & 0.320 & 26.855 \\
\hline 13 & 0.452 & 4.36 & 0.540 & 35.355 & 0.280 & 1.241 & 0.340 & 22.370 \\
\hline 14 & 0.486 & 7.899 & 0.540 & 30.225 & 0.221 & 1.119 & 0.520 & 24.895 \\
\hline 15 & 0.562 & 13.047 & 0.800 & 27.335 & 0.446 & 1.191 & 0.260 & 13.425 \\
\hline 16 & 0.404 & 11.075 & 0.400 & 29.935 & 0.325 & 1.273 & 0.340 & 11.810 \\
\hline 17 & 0.587 & 6.029 & 0.300 & 31.615 & 0.153 & 0.242 & 0.340 & 17.945 \\
\hline 18 & 0.478 & 10.245 & 0.260 & 26.700 & 0.241 & 0.752 & 0.100 & 16.915 \\
\hline 19 & 0.477 & 5.49 & 0.380 & 23.130 & 0.125 & 0.224 & 0.100 & 15.930 \\
\hline 20 & 0.533 & 10.016 & 0.640 & 28.235 & 0.253 & 0.447 & 0.320 & 13.915 \\
\hline Ave. & 0.523 & 7.327 & 0.426 & 23.567 & 0.289 & 1.457 & 0.3630 & 16.485 \\
\hline Std. & 0.084 & 3.861 & 0.140 & 11.357 & 0.133 & 1.492 & 0.210 & 6.348 \\
\hline
\end{tabular}


Table A2. Inslab mainshock-aftershock record information

\begin{tabular}{|c|c|c|c|c|c|c|c|c|}
\hline \multirow{2}{*}{$\begin{array}{l}\text { Sequence } \\
\text { Number }\end{array}$} & \multicolumn{4}{|c|}{ Mainshock } & \multicolumn{4}{|c|}{ Major Aftershock } \\
\hline & $\operatorname{PGA}(\mathrm{g})$ & $\mathbf{A I}(\mathbf{m} / \mathbf{s})$ & Period (s) & Duration (s) & PGA(g) & $\begin{array}{c}\mathbf{A I} \\
(\mathbf{m} / \mathbf{s})\end{array}$ & Period (s) & Duration (s) \\
\hline 1 & 0.762 & 14.421 & 0.360 & 10.430 & 0.246 & 0.223 & 0.160 & 2.490 \\
\hline 2 & 0.395 & 2.958 & 0.140 & 10.150 & 0.148 & 0.082 & 0.160 & 4.260 \\
\hline 3 & 0.541 & 5.996 & 0.780 & 38.890 & 0.307 & 0.906 & 0.320 & 38.950 \\
\hline 4 & 0.811 & 4.91 & 0.280 & 39.760 & 0.354 & 0.879 & 0.520 & 32.450 \\
\hline 5 & 0.508 & 3.697 & 0.160 & 32.780 & 0.484 & 4.802 & 1.360 & 19.770 \\
\hline 6 & 0.413 & 3.578 & 0.180 & 43.800 & 0.552 & 2.790 & 0.500 & 27.960 \\
\hline 7 & 0.573 & 3.058 & 0.620 & 17.530 & 0.267 & 1.017 & 0.160 & 25.250 \\
\hline 8 & 0.577 & 3.551 & 0.620 & 15.920 & 0.342 & 1.448 & 0.520 & 18.040 \\
\hline 9 & 0.523 & 2.677 & 0.380 & 25.990 & 0.156 & 0.729 & 0.400 & 40.320 \\
\hline 10 & 0.498 & 2.61 & 0.520 & 27.840 & 0.172 & 0.724 & 0.340 & 42.220 \\
\hline 11 & 0.384 & 4.453 & 0.620 & 32.230 & 0.253 & 2.339 & 0.180 & 32.430 \\
\hline 12 & 0.649 & 12.806 & 0.520 & 29.100 & 0.403 & 6.542 & 0.480 & 37.030 \\
\hline 13 & 0.521 & 2.361 & 0.260 & 21.910 & 0.149 & 0.610 & 0.400 & 36.940 \\
\hline 14 & 0.518 & 3.327 & 0.520 & 26.730 & 0.195 & 0.880 & 0.340 & 34.370 \\
\hline 15 & 0.420 & 7.261 & 0.500 & 49.890 & 0.262 & 3.151 & 0.520 & 61.680 \\
\hline 16 & 0.410 & 6.294 & 0.740 & 36.910 & 0.348 & 2.470 & 0.400 & 47.790 \\
\hline 17 & 0.469 & 2.589 & 0.540 & 10.810 & 0.342 & 0.816 & 0.360 & 7.010 \\
\hline 18 & 0.649 & 4.875 & 0.580 & 7.490 & 0.499 & 1.125 & 0.480 & 3.580 \\
\hline 19 & 0.678 & 7.521 & 0.680 & 22.990 & 0.638 & 3.983 & 0.300 & 22.350 \\
\hline 20 & 0.515 & 5.511 & 0.620 & 26.240 & 0.559 & 2.872 & 0.120 & 26.010 \\
\hline Ave. & 0.541 & 5.223 & 0.481 & 26.370 & 0.334 & 1.919 & 0.401 & 28.045 \\
\hline Std. & 0.116 & 3.193 & 0.189 & 11.670 & 0.144 & 1.651 & 0.256 & 15.335 \\
\hline
\end{tabular}

Table A3. Interface mainshock-aftershock record information

\begin{tabular}{|c|c|c|c|c|c|c|c|c|}
\hline \multirow{2}{*}{$\begin{array}{l}\text { Sequence } \\
\text { Number }\end{array}$} & \multicolumn{4}{|c|}{ Mainshock } & \multicolumn{4}{|c|}{ Major Aftershock } \\
\hline & PGA(g) & $\mathbf{A I}(\mathbf{m} / \mathbf{s})$ & Period (s) & Duration (s) & PGA(g) & $\mathbf{A I}(\mathbf{m} / \mathbf{s})$ & $\begin{array}{l}\text { Period } \\
\text { (s) }\end{array}$ & Duration (s) \\
\hline 1 & 0.328 & 3.402 & 0.460 & 38.190 & 0.220 & 1.346 & 0.360 & 29.550 \\
\hline 2 & 0.446 & 7.327 & 0.480 & 38.510 & 0.352 & 3.681 & 0.460 & 24.740 \\
\hline 3 & 0.366 & 3.993 & 0.340 & 73.680 & 0.487 & 3.902 & 0.380 & 23.710 \\
\hline 4 & 0.333 & 5.111 & 0.480 & 79.520 & 0.484 & 3.987 & 0.480 & 29.410 \\
\hline 5 & 0.605 & 16.498 & 0.540 & 34.250 & 0.451 & 6.383 & 0.460 & 24.130 \\
\hline 6 & 0.299 & 3.818 & 0.400 & 39.000 & 0.190 & 1.507 & 0.340 & 28.280 \\
\hline 7 & 0.469 & 8.456 & 0.360 & 52.270 & 0.408 & 4.206 & 0.380 & 24.780 \\
\hline 8 & 0.389 & 8.76 & 0.420 & 46.970 & 0.340 & 4.463 & 0.420 & 23.520 \\
\hline 9 & 0.555 & 18.947 & 0.580 & 104.220 & 0.555 & 11.438 & 0.380 & 93.310 \\
\hline 10 & 0.379 & 13.998 & 0.560 & 96.120 & 0.286 & 5.287 & 0.500 & 103.450 \\
\hline 11 & 0.417 & 20.933 & 0.460 & 115.730 & 0.444 & 5.398 & 0.420 & 22.410 \\
\hline 12 & 0.416 & 14.268 & 0.560 & 115.750 & 0.348 & 2.887 & 0.420 & 26.220 \\
\hline 13 & 0.762 & 36.22 & 0.580 & 105.300 & 0.383 & 4.683 & 0.200 & 26.130 \\
\hline 14 & 0.411 & 12.688 & 1.340 & 110.250 & 0.250 & 1.464 & 0.180 & 28.150 \\
\hline 15 & 0.357 & 11.441 & 0.400 & 114.200 & 0.305 & 2.794 & 0.540 & 31.610 \\
\hline 16 & 0.536 & 22.679 & 0.660 & 110.790 & 0.589 & 6.368 & 0.520 & 20.630 \\
\hline 17 & 0.484 & 17.855 & 0.420 & 104.090 & 0.231 & 1.595 & 0.500 & 47.540 \\
\hline 18 & 0.302 & 6.302 & 0.580 & 105.940 & 0.132 & 0.800 & 0.420 & 36.620 \\
\hline 19 & 0.470 & 13.536 & 0.480 & 102.910 & 0.251 & 1.792 & 0.460 & 173.230 \\
\hline 20 & 0.432 & 11.941 & 0.460 & 102.310 & 0.282 & 1.564 & 0.140 & 178.840 \\
\hline Ave. & 0.438 & 12.909 & 0.528 & 84.500 & 0.349 & 3.777 & 0.398 & 49.813 \\
\hline Std. & 0.110 & 7.774 & 0.203 & 30.074 & 0.121 & 2.442 & 0.108 & 47.396 \\
\hline
\end{tabular}

